\title{
p38 Inhibition Decreases Tau Toxicity in Microglia and Improves Their Phagocytic Function
}

\author{
Juan R. Perea ${ }^{1,2,3}$ - Marta Bolós ${ }^{1,2}$ - $\cdot$ Raquel Cuadros ${ }^{1} \cdot$ Esther García $^{1} \cdot$ Vega García-Escudero ${ }^{1,4}(\mathbb{0}$. \\ Félix Hernández $^{1,2,5} \mathbb{D}$ - Róisín M. McManus ${ }^{3} \mathbb{D}$ - Michael T. Heneka ${ }^{3}$ - Jesús Avila ${ }^{1,2}$ (D)
}

Received: 26 August 2021 / Accepted: 21 December 2021 / Published online: 10 January 2022

(c) The Author(s) 2022

\begin{abstract}
Alzheimer's disease (AD) and other tauopathies are histopathologically characterized by tau aggregation, along with a chronic inflammatory response driven by microglia. Over the past few years, the role of microglia in AD has been studied mainly in relation to amyloid- $\beta(\mathrm{A} \beta)$ pathology. Consequently, there is a substantial knowledge gap concerning the molecular mechanisms involved in tau-mediated toxicity and neuroinflammation, thus hindering the development of therapeutic strategies. We previously demonstrated that extracellular soluble tau triggers p38 MAPK activation in microglia. Given the activation of this signaling pathway in $\mathrm{AD}$ and its involvement in neuroinflammation processes, here we evaluated the effect of $\mathrm{p} 38$ inhibition on primary microglia cultures subjected to tau treatment. Our data showed that the toxic effect driven by tau in microglia was diminished through p38 inhibition. Furthermore, p38 blockade enhanced microglia-mediated tau phagocytosis, as reflected by an increase in the number of lysosomes. In conclusion, these results contribute to our understanding of the functions of $\mathrm{p} 38$ in the central nervous system (CNS) beyond tau phosphorylation in neurons and provide further insights into the potential of p38 inhibition as a therapeutic strategy to halt neuroinflammation in tauopathies.
\end{abstract}

Keywords Tau $\cdot \mathrm{p} 38 \cdot$ Microglia $\cdot$ Tauopathies $\cdot$ Alzheimer's disease $\cdot$ Neuroinflammation

\section{Introduction}

Alzheimer's disease (AD) is the most common form of dementia, affecting 47 million people worldwide. It is the main cause of dependence in older adults and the fifth cause

Jesús Avila

javila@cbm.uam.es

1 Department of Molecular Neuropathology, Centro de Biología Molecular "Severo Ochoa" (UAM-CSIC), 28049 Madrid, Spain

2 Center for Networked Biomedical Research On Neurodegenerative Diseases (CIBERNED), 28031 Madrid, Spain

3 German Center for Neurodegenerative Diseases (DZNE), 53127 Bonn, Germany

4 Department of Anatomy, Histology and Neurosciences, Faculty of Medicine, Universidad Autónoma de Madrid (UAM), 28029 Madrid, Spain

5 Department of Molecular Biology, Faculty of Sciences, Universidad Autónoma de Madrid (UAM), 28049 Madrid, Spain of death. Although this disease has an incredibly high socioeconomic burden, there are still no effective therapies [1, 2]. $\mathrm{AD}$ is characterized by the presence of senile plaques (comprised of amyloid- $\beta$ peptide $(A \beta)$ ) [3-5] and neurofibrillary tangles (NFTs) (formed by the aggregation of hyperphosphorylated tau) [6-8] in the brain, which cause synaptic dysfunction, neuron loss and marked glial activation [9].

Tau is a microtubule-associated protein that regulates axonal transport and stabilizes and spatially organizes the microtubules of neurons [10, 11], among other functions [12]. Tau protein is subjected to numerous post-translational modifications, phosphorylation being the most recurrent [13]. This process is physiologically regulated throughout life. However, in some neurodegenerative diseases called tauopathies (such as AD), tau is hyperphosphorylated [14]. The state of phosphorylation plays a very important role in regulating the physiological function of tau, since it reduces the binding affinity of tau to microtubules and promotes its aggregation, thus compromising the integrity of neurons $[15,16]$. On the other hand, several authors have reported that NFTs are not as toxic as previously believed, thereby suggesting that small aggregates and soluble tau species are the main drivers of neurodegeneration 
in tauopathies [17-25]. In this regard, various mechanisms can release tau into the extracellular space, where it interacts with other neurons [26-29] or glial cells such as astrocytes [30, 31] and microglia $[32,33]$.

Microglia are the resident macrophages of the brain [34, 35 ] and make up 5-12\% of central nervous system (CNS) cells [36]. Alois Alzheimer was the first to recognize the involvement of glia in the disease that bears his name [37]. However, it was in the 1990s that microglia were shown to interact with $\mathrm{A} \beta$ and tau $[38,39]$. For the last thirty years, the scientific community, supported by the amyloid hypothesis, has focused on studying the contribution of $A \beta$ to neuroinflammation, while less attention has been paid to the association between microglia and tau pathology. In this context, Ising et al. recently showed that tau promotes NLRP3 inflammasome activation [40]. Moreover, previous work by our group demonstrated that tau induces a pro-inflammatory response in microglia through p38 MAPK activation [41].

Mitogen-activated protein kinase (MAPK) signal transduction pathways are ubiquitous and highly evolutionarily conserved mechanisms that coordinate and integrate responses to diverse stimuli (e.g., pathogen-associated molecular patterns (PAMPs), danger-associated molecular patterns (DAMPs), cytokines and environmental stresses) and are thus associated with various cellular processes [42]. The p38 MAPK subfamily, comprising four isoforms encoded by MAPK14 (p38 $\alpha$ ), MAPK11 (p38ß), MAPK12

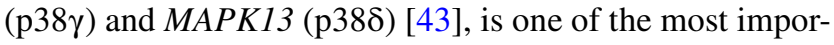
tant signaling pathways in inflammation [44]. p38 activation in $\mathrm{AD}$ [45] has been fundamentally attributed to its ability to phosphorylate tau in neurons [46-49], while its function in microglia has not been fully elucidated.

Here we show that extracellular tau exerts a toxic effect in microglia that is reversed by pharmacological inhibition of p38. Furthermore, p38 blockade promotes an increase in tau phagocytosis, although it diminishes tau-mediated microglial migration. These results support the notion that targeting p38 signaling might offer a potential therapeutic strategy through which to improve microglial function and prevent neuroinflammation in tauopathies.

\section{Materials and Methods}

\section{Recombinant Tau Preparation}

pRKT42, which encodes full-length tau protein of human origin (2N4R), was transformed into lipopolysaccharide (LPS)-free ClearColi (BL21(DE3)) cells (Lucigen, Cat\#60810) following the manufacturer's instructions. Single colonies were grown in LB medium with $100 \mu \mathrm{g} / \mathrm{ml}$ of ampicillin, and $0.4 \mathrm{mM}$ IPTG was added when $\mathrm{OD}_{600}$ reached 0.6-0.8. Four hours later, bacteria were pelleted
(20 min, 1,000 g, $4{ }^{\circ} \mathrm{C}$ ) and sonicated in extraction buffer (0.1 M MES, 2 mM EGTA, $0.5 \mathrm{mM} \mathrm{MgCl}{ }_{2}, 0.5 \mathrm{M} \mathrm{NaCl}$, $5 \mathrm{mM} \beta$-mercaptoethanol, and $1 \mathrm{mM}$ PMSF). The sonicated product was then centrifuged $(10 \mathrm{~min}, 23,700 \mathrm{~g}$, $4{ }^{\circ} \mathrm{C}$ ) and the supernatant was boiled for $10 \mathrm{~min}$ to prevent possible contamination of endogenous enzymatic activities. The boiled sample was incubated on ice for $5 \mathrm{~min}$ and subsequently centrifuged $\left(30 \mathrm{~min}, 23,700 \mathrm{~g}, 4{ }^{\circ} \mathrm{C}\right)$. Tris was then added to the supernatant until $\mathrm{pH}=11$.

To induce tau precipitation, the sample was stirred for $1 \mathrm{~h}$ at $4{ }^{\circ} \mathrm{C}$ in a magnetic mixer and $\left(\mathrm{NH}_{4}\right)_{2} \mathrm{SO}_{4}$ was added until reaching $50 \%$ saturation. Next, the sample was centrifuged $\left(1 \mathrm{~h}, 23,700 \mathrm{~g}, 4^{\circ} \mathrm{C}\right)$ and the pellet was resuspended in PBS. The resuspension was dialyzed in PBS with a Spectra/Por3 membrane (Repligen, Cat\#132720) overnight at $4{ }^{\circ} \mathrm{C}$ in a magnetic mixer. The next day, the dialyzed product was incubated for $30 \mathrm{~min}$ at $37{ }^{\circ} \mathrm{C}$ while shaking with $10 \mu \mathrm{g} / \mathrm{ml}$ of RNase A (Roche, Cat\#10109169001). To stop the enzymatic activity of the RNase and remove it, the sample was incubated for $1 \mathrm{~min}$ at $100{ }^{\circ} \mathrm{C}$ and centrifuged (1 min, 15,900 g, $4{ }^{\circ} \mathrm{C}$ ).

To efficiently remove the remaining endotoxins, the supernatant was subjected to Triton X-114 phase separation. First, Triton X-114 was added at a concentration of $1 \%$ and the sample was incubated for $30 \mathrm{~min}$ at $4{ }^{\circ} \mathrm{C}$ in a rotating shaker with a vortex step every $5 \mathrm{~min}$. The sample was then incubated for $10 \mathrm{~min}$ at $56^{\circ} \mathrm{C}$ in a water bath and centrifuged $\left(10 \mathrm{~min}, 20,000 \mathrm{~g}, 25^{\circ} \mathrm{C}\right)$ to obtain the liquid phase. This procedure was repeated three times and the liquid phase of the third cycle was processed through a Pierce detergent removal spin column (Thermo Fisher, Cat\#87779), following the manufacturer's instructions. The eluted volume was passed through a polymyxin B-agarose (Sigma Aldrich, Cat\#P1411) endotoxin removal column, and endotoxin levels were quantified by LAL assay (HyCult Biotech, RRID:AB_10130891).

For some experiments, purified tau was labeled with sulfoindocyanine Cy5 (GE Healthcare, Cat\#PA25001), following the manufacturer's recommendations. Briefly, $1 \mathrm{ml}$ of recombinant tau protein $(1 \mathrm{mg} / \mathrm{ml})$, which comprises mainly monomers and dimers [50], was mixed with a sample of Cy 5 dye for $1 \mathrm{~h}$ at room temperature. To remove the excess of free-dye, the mixture was dialyzed in PBS overnight at $4{ }^{\circ} \mathrm{C}$ and filtered through a Sephadex G-50 column. Finally, each eluted fraction was tested for the presence of tau by dot blot, and tau-containing fractions were combined.

\section{Primary Microglia Cultures}

Mice were housed in $403(\mathrm{~W}) \times 165(\mathrm{D}) \times 174(\mathrm{H}) \mathrm{mm}$ cages (4-5 mice/cage) at the specific pathogen-free animal facility of the "Centro de Biología Molecular Severo Ochoa." They 
had access to food and water ad libitum and were maintained on a 12/12 h light/dark cycle in a temperature-controlled environment. Animal housing and maintenance protocols followed the guidelines of the Council of Europe Convention ETS123, revised as indicated in Directive 86/609/EEC. Animal experiments were performed under protocols (P15/ P16/P18/P22) approved by the Institutional Animal Care and Utilization Committee (PROEX 291/15) and following ARRIVE guidelines.

Microglia were cultured from newborn C57BL/6 J (Charles River, RRID:MGI:6151402) mice (P0-P3). Animals were decapitated, and brains were dissected in cold $\mathrm{Ca}^{2+} / \mathrm{Mg}^{2+}$-free HBSS and stripped of meninges. The tissue was then digested with $0.25 \%$ trypsin for $10 \mathrm{~min}$ at $37{ }^{\circ} \mathrm{C}$. Trypsinization was stopped by the addition of the medium used for this cell culture: DMEM supplemented with $1 \%$ Glutamax (Gibco, Cat\#35050-038), 10\% FBS (Gibco, Cat\#26140-079), $100 \mathrm{U} / \mathrm{mL}$ of penicillin and $0.1 \mathrm{mg} / \mathrm{mL}$ of streptomycin (Gibco, Cat\#15240-062). Next, $0.2 \mathrm{mg} / \mathrm{ml}$ DNase (Roche, Cat\#11284932001) was added to the digested tissue and centrifuged $\left(10 \mathrm{~min}, 300 \mathrm{~g}, 4^{\circ} \mathrm{C}\right)$. A single-cell suspension of the pellet was obtained by repeated pipetting. Subsequently, cells were passed through a 40- $\mu \mathrm{m}$ nylon filter and seeded into $75 \mathrm{~cm}^{2}$ flasks coated with $0.1 \mathrm{mg} / \mathrm{ml}$ poly-Llysine (Sigma Aldrich, Cat\#P9155) (2 brains/flask), which were maintained at $37{ }^{\circ} \mathrm{C}$ in humidified $5 \% \mathrm{CO}_{2}-95 \%$ air. The next day, the plating medium was discarded, the flasks were washed three times with PBS, and fresh medium supplemented with $10 \%$ L929 conditioned medium was added. Microglia were collected after 7-10 days by shake off and centrifugation (10 min, $300 \mathrm{~g}$, room temperature).

\section{Live-Cell Imaging}

One hundred thousand cells/well were seeded on an M24 plate. After 2 days, cells were treated with $1 \mu \mathrm{g} / \mathrm{ml}$ of LPS (from E. coli O55:B5, Sigma Aldrich, Cat\#L2880), $0.5 \mu \mathrm{M}$ tau, or PBS (control). Some of the experiments were subjected to a 30 min pre-treatment with $20 \mu \mathrm{M}$ SB203580 (Sigma Aldrich, Cat\#S8307), $10 \mu \mathrm{M}$ cytochalasin D (Sigma Aldrich, Cat\#C2618) or vehicle (DMSO). The plate was immediately placed in an Incucyte S3 system (Sartorius) and 9 images/well were taken every hour for $24-48 \mathrm{~h}$ with a $10 \times$ objective. Automated image processing (Supplementary Fig. S1) and quantification were carried out by the integrated controller unit (Sartorius) using Incucyte S3 v.2017A software. The total sum of the Cy5 signal of all cells in each image $\left(\left(\mathrm{RCU} \times \mu^{2}\right) /\right.$ image $)$ was calculated to analyze tau-Cy5 internalization by microglia. Cell death events were visualized by adding $250 \mathrm{nM}$ Cytotox Red reagent (Sartorius, Cat\#4632), following the manufacturer's instructions. Confluence analysis was performed by calculating the percentage of area occupied by the cells.

\section{Western Blot}

One hundred thousand cells/well were seeded on an M24 plate. After 2 days, cells were pre-treated for $30 \mathrm{~min}$ with $20 \mu \mathrm{M}$ SB203580 (Sigma Aldrich, Cat\#S8307), $10 \mu \mathrm{M}$ cytochalasin D (Sigma Aldrich, Cat\#C2618) or vehicle (DMSO), and $0.5 \mu \mathrm{M}$ tau or PBS (control) was subsequently added for $30 \mathrm{~min}$. Afterwards, cells were washed three times with PBS to remove excess tau. Finally, the samples were lysed using the RIPA buffer $(50 \mathrm{mM}$ Tris- $\mathrm{HCl} \mathrm{pH} 7.4$, $150 \mathrm{mM} \mathrm{NaCl}, 1 \%$ Triton X-100, $0.5 \%$ sodium deoxycholate, and $0.1 \%$ SDS) with a mixture of protease (cOmplete, Roche, Cat\#11697498001) and phosphatase (0.1 mM okadaic acid and $5 \mathrm{mM}$ orthovanadate) inhibitors. After a centrifugation step ( $5 \mathrm{~min}, 845 \mathrm{~g}, 4^{\circ} \mathrm{C}$ ), the protein concentration of the supernatant was determined using the BCA assay (Thermo Fisher, Cat\#23225).

$5 \times$ Laemmli buffer $(0.125$ M Tris- $\mathrm{HCl}$ pH $6.8,20 \%$ glycerol, 5\% SDS, $0.004 \%$ bromophenol blue, and $2 \%$ $\beta$-mercaptoethanol) was added to the protein extracts, which were denatured at $100{ }^{\circ} \mathrm{C}$ for $5 \mathrm{~min}$. Proteins were then separated by standard SDS-PAGE electrophoresis in 10-12\% polyacrylamide gels. They were then transferred to polyvinylidene difluoride membranes (Millipore, Cat\#IPVH00010) using a Mini-PROTEAN system (Bio-Rad) at a constant amperage of $150 \mathrm{~mA}$ for $50 \mathrm{~min}$ (90 min for Hsp27 and phospho-Hsp27 immunoblotting). Membranes were blocked with 5\% BSA in $0.1 \%$ TBS-T for $2 \mathrm{~h}$ at room temperature and incubated overnight at $4{ }^{\circ} \mathrm{C}$ with primary antibodies. The following day, membranes were washed 3 times with $0.1 \%$ TBS-T and incubated with secondary antibodies for $2 \mathrm{~h}$ at room temperature. Finally, membranes were subjected to 3 washes with $0.1 \%$ TBS-T before being developed with ECL (PerkinElmer, Cat\#NEL105001EA) and photographed on an ImageQuant LAS 4000 mini system (GE Healthcare). The signal intensity was quantified by densitometry using Fiji v.2.1.0/1.53c (RRID:SCR_002285). To correct for possible loading errors, the densitometry values obtained were normalized with loading controls.

\section{Lentiviral Stock Preparation}

HEK 293 T cells (RRID:CVCL_1926. Authenticated by STR profiling, confirmed for mycoplasma negative, and not listed as commonly misidentified cell line by the International Cell Line Authentication Committee) were seeded at a passage number lower than 10 in 100-mm dishes and co-transfected at $85 \%$ confluency with $5 \mu \mathrm{g}$ of the packaging plasmid pCMVR8.74 (RRID:Addgene_22036), $2 \mu \mathrm{g}$ of the VSV-G envelope protein plasmid pMD2.G (RRID:Addgene_12259) and $5 \mu \mathrm{g}$ of the corresponding lentivector plasmid pWPI (RRID:Addgene_12254) or pWPI-Tau (kindly provided by Prof. Kenneth S. Kosik. Encodes full-length tau (2N4R) and 
GFP reporter) using Lipofectamine Plus (Thermo Fisher, Cat\#18324-012), following the manufacturer's instructions. The next day, the transfection medium was replaced with $5 \mathrm{ml}$ of fresh microglia medium. After $24 \mathrm{~h}$, the medium was passed through a $0.45 \mu \mathrm{m}$ low binding pore filter and working titers $\left(1.06-1.73 \times 10^{6}\right.$ infective units/ml) were quantified by flow cytometry using a FACSCalibur 4CA (BD) and FlowJo v.10.4 (RRID:SCR_008520).

\section{Bv-2 Infection}

The Bv-2 microglial cell line (RRID:CVCL_0182. Not listed as commonly misidentified cell line by the International Cell Line Authentication Committee) was grown in modified RPMI medium (10 mM HEPES, $4.5 \mathrm{~g} / 1$ of glucose, and $1.5 \mathrm{~g} / 1$ of sodium bicarbonate) supplemented with $2 \mathrm{mM}$ L-glutamine, $1 \mathrm{mM}$ sodium pyruvate, $50 \mu \mathrm{g} /$ $\mathrm{ml}$ of gentamycin and 10\% FBS (Gibco, Cat\#26140-079). Two hundred thousand cells/well were seeded at a passage number lower than 10 on an M6 plate. Two days later, lentiviral vectors were used to transfect the cells at a MOI of 1 in the presence of $8 \mu \mathrm{g} / \mathrm{ml}$ of polybrene (Sigma Aldrich, Cat\#TR-1003). The medium was replaced every day and Green fluorescent protein (GFP) reporter expression was visualized under a microscope after $72 \mathrm{~h}$. The percentage of infection was quantified by flow cytometry using a FACSCalibur 4CA (BD) and FlowJo v.10.4 (RRID:SCR_008520). Cells were then treated with $0.5 \mu \mathrm{M}$ tau or PBS (control) for 30 min. Afterwards, they were washed three times with PBS to remove excess tau. Finally, the samples were lysed using the RIPA buffer with a mixture of protease and phosphatases inhibitors (composition detailed above). After a centrifugation step ( $5 \mathrm{~min}, 845 \mathrm{~g}, 4^{\circ} \mathrm{C}$ ), the protein concentration of the supernatant was determined by the BCA assay (Thermo Fisher, Cat\#23225).

\section{Tau Internalization Assay}

Fifty thousand cells/well were seeded on an M96 black plate. After 2 days, cells were pre-treated for 30 min with $20 \mu \mathrm{M}$ SB203580 (Sigma Aldrich, Cat\#S8307) or vehicle (DMSO), and $0.5 \mu \mathrm{M}$ tau-Cy5 or PBS-Cy5 (control) was subsequently added at different time points (from 0.5 to $6 \mathrm{~h}$ ). The culture medium was then removed from the wells and cells were washed three times with PBS. Finally, Cy5 fluorescence was measured in an Infinite M200 PRO plate reader (Tecan, RRID:SCR_019033) at an excitation wavelength of $630 \mathrm{~nm}$ and emission wavelength of $680 \mathrm{~nm}$.

\section{Lysosomal Mass Quantification}

Three hundred thousand cells/well were seeded on an M24 plate. After 2 days, cells were pre-treated for $30 \mathrm{~min}$ with
$20 \mu$ M SB203580 (Sigma Aldrich, Cat\#S8307) or vehicle (DMSO), and $0.5 \mu \mathrm{M}$ tau or PBS (control) was subsequently added for 6 h. $75 \mathrm{nM}$ Lysotracker Red (Thermo Fisher, Cat\#L7528) was then added for $45 \mathrm{~min}$, and cells were washed twice with PBS. Trypsin was then used to lift cells from the plate and cells were again washed twice with PBS by centrifugation ( $5 \mathrm{~min}, 150 \mathrm{~g}, 4{ }^{\circ} \mathrm{C}$ ). Finally, cells were resuspended in $200 \mu \mathrm{l}$ of PBS and analyzed using a FACSCanto II flow cytometer (BD) and FlowJo v.10.4 (RRID:SCR_008520). 1 g/ml DAPI (Merck, Cat\#268298) was used to exclude dead cells from the analysis.

\section{Microglia Migration Assay}

One hundred cells were seeded onto an $8-\mu \mathrm{m}$ pore size insert (Merck, Cat\#MCEP24H48). Inserts were placed into an M24 plate containing $300 \mu \mathrm{l}$ of medium with $0.5 \mu \mathrm{M}$ tau or PBS (control) and $20 \mu \mathrm{M} \mathrm{SB} 203580$ (Sigma Aldrich, Cat\#S8307) or vehicle (DMSO). After $3 \mathrm{~h}$ of incubation, inserts were removed and the medium was transferred to $1.5 \mathrm{ml}$ tubes, which were centrifuged $\left(5 \mathrm{~min}, 150 \mathrm{~g}, 4{ }^{\circ} \mathrm{C}\right)$. Pellet was resuspended in $10 \mu \mathrm{l}$ trypan blue and cell counting was carried out using a 10-well hemocytometer (Kova International, Cat\#87144E).

\section{Immunofluorescence}

Sixty thousand cells/well were seeded on an M24 plate with $12 \mathrm{~mm}$ coverslips. After 2 days, cells were pre-treated for 30 min with $20 \mu \mathrm{M}$ SB203580 (Sigma Aldrich, Cat\#S8307) or vehicle (DMSO), and $0.5 \mu \mathrm{M}$ tau-Cy5 or PBS-Cy5 (control) was subsequently added for $6 \mathrm{~h}$. Afterwards, cells were washed three times with PBS to remove excess tau-Cy5, fixed in 4\% paraformaldehyde (Electron Microscopy Sciences, Cat\#15710) for $15 \mathrm{~min}$ at room temperature and washed again three times with PBS. Cells were then permeabilized with PBS containing $0.2 \%$ Triton X-100 for $10 \mathrm{~min}$ at room temperature and washed three times with PBS. After 30 min of blocking with $1 \%$ BSA in PBS-T at room temperature, cells were washed three times with PBS and stained with phalloidin 488 (Thermo Fisher, Cat\#A12379) at 1:300 dilution in PBS for $1 \mathrm{~h}$ at room temperature. Finally, cells were washed three times in PBS, nuclei were labeled with $1 \mu \mathrm{g} / \mathrm{ml}$ DAPI (Merck) for $10 \mathrm{~min}$ at room temperature and rinsed with PBS.

Images were obtained using the SpinSR10 confocal system coupled to an IX83 inverted microscope (Olympus) with a $40 \times$ objective. Each image is an overlay of 37 stacks with a separation of $1 \mu \mathrm{m}$ between them. The proportion of migrating cells (characterized by the presence of a large filopodium) was quantified manually using the Cell Counter tool of Fiji. The occupied area was measured by drawing the contour of each cell individually. Fifty cells were 
analyzed for each experimental condition of three independent experiments.

\section{Statistical Analysis}

Data were evaluated using GraphPad Prism v.9.0.0 (RRID:SCR_002798) of at least three independent experiments. The presence of outliers was checked using the Grubbs test. Subsequently, Shapiro-Wilk and D'AgostinoPearson tests were used to verify that the remaining values were adjusted to a normal distribution. The area under the curve (AUC) was calculated when analyzing a variable over time. For the comparison between two experimental groups, data were analyzed by Student's $t$ test (two-tailed). One and two-way analysis of variance (ANOVA) tests were applied to compare more than two experimental groups, and post hoc comparisons were performed using Tukey's multiple comparison test. Details of the number of independent cell culture experiments $(n)$, data representation (mean \pm standard error of the mean (SEM)), the statistical test used, and significance levels are provided in the caption of each figure. This work is an exploratory study and it was not preregistered. No randomization, sample calculation or blinding was performed.

\section{Results}

\section{Tau Exerts a Toxic Effect on Microglia}

We previously reported that extracellular tau is internalized by microglia $[33,51]$. However, little is known about its consequences at the cellular level. Using live-cell imaging, we observed that microglia treated with tau of human origin acquired an amoeboid morphology and showed vacuoles, which is characteristic of an activated phenotype against harmful stimuli such as LPS (Fig. 1A-C). Confluence analysis also revealed a decrease in the area occupied by microglia in the presence of tau after $6 \mathrm{~h}$ of treatment compared with the LPS condition (Fig. 1D-E). This observation may indicate that tau compromises the survival of these cells. To address this issue, we used Cytotox Red, a highly sensitive cyanine nucleic acid dye that allows the evaluation of cell death. In this regard, we observed that the decrease in confluence in microglia subjected to tau treatment was accompanied by an increase in cell death (Fig. 1F-G and Supplementary video S1). This result confirms that tau exerts a toxic effect on microglia, as has been described in other cell types of the CNS such as neurons [52] (Supplementary Fig. S2). Given that cytotoxicity did not increase significantly between 24 and $48 \mathrm{~h}$ (Fig. 1F), the rest of the live-cell imaging experiments had a maximum duration of $24 \mathrm{~h}$.

\section{Phagocytosis Inhibition Decreases Tau-Mediated Cytotoxicity in Microglia}

The toxic effect of tau protein could be due to its internalization by microglia. Phagocytosis is one of the essential functions of these cells since it intervenes in the correct development of the CNS and it is fundamental to eliminate pathogens and protein aggregates that accumulate with age [53]. In this context, tau can be released by neurons into the extracellular space and subsequently be internalized by neighboring cells [54]. To reinforce the notion that tau protein is phagocytosed by microglia, we subjected these cells to cytochalasin D (CytoD) treatment, a well-known phagocytosis inhibitor [55]. We next added tau labeled with Cy5 (tau-Cy5) to analyze the internalization of this protein, observing that phagocytosis inhibition prevented microgliamediated tau uptake (Fig. 2A-D and Supplementary video S2). The diffuse signal observed in Fig. 2A and B corresponded to extracellular tau-Cy5 added to the cell culture prior to image acquisition. Also, to determine whether tau internalization gave rise to cell death, we analyzed cytotoxicity under phagocytosis inhibition. Although CytoD per se caused some toxicity, this drug significantly, but not totally, decreased tau-mediated cytotoxicity in microglia (Fig. 2E-J and Supplementary video S3).

\section{Tau Activates p38 Independently of Its Internalization by Microglia}

After describing that phagocytosis blockade partially reduced the toxic effect of tau, we questioned whether the inflammatory response of these cells was also decreased under this condition. In this regard, p38 MAPK is one of the molecular triggers of inflammation [44], and previous work by our group demonstrated that tau induces p38 activation in microglia [41]. Taking this into consideration, we sought to determine whether the inhibition of tau phagocytosis reduced p38 activation. To this end, microglia were subjected to a 30 min pre-treatment with CytoD or SB203580 (SB), the latter a widely used p38 inhibitor. The cells were then incubated in the presence of tau for a further $30 \mathrm{~min}$. Western blot analysis (Fig. 3A) showed that both p38 (Fig. 3B) and its downstream target MAPKactivated protein kinase 2 (MK2) (Fig. 3C) were activated despite blocking phagocytosis. This result indicates that tau promotes the activation of microglia without the need for its internalization.

\section{p38 Is Specifically Activated in the Presence of Extracellular Tau}

We also wanted to demonstrate whether endogenous tau expression in microglia (that do not tau express per se [56, 
Fig. 1 Tau exerts a toxic effect on microglia. Representative images of microglia treated with PBS (control) (A), LPS

(B) or tau protein (C) for $48 \mathrm{~h}$. Cytotox Red labeling indicates cytotoxicity. (D-E) Confluence analysis shows a dramatic increase in cell activation from 0 to $6 \mathrm{~h}$ with LPS and tau treatments. (F-G) Cytotoxicity analysis reveals that tau protein is toxic for microglia. $n=4$. Graphs show mean \pm SEM. $* * * p<0.001$ from one-way ANOVA. Scale bar, $100 \mu \mathrm{m}$. AUC, area under the curve; LPS, lipopolysaccharide; PBS, phosphate-buffered saline

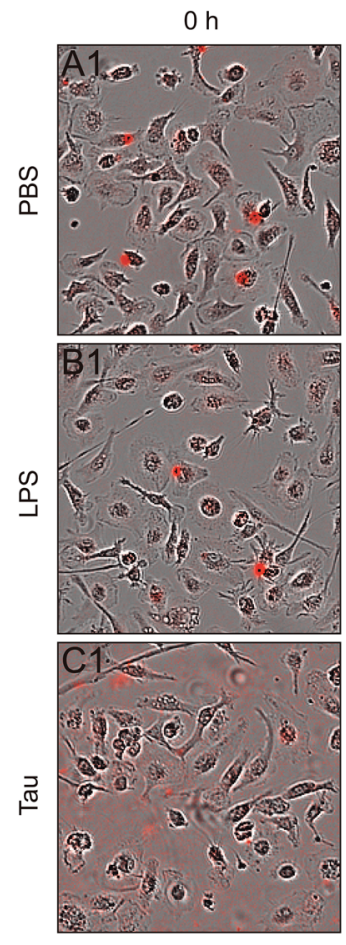

D

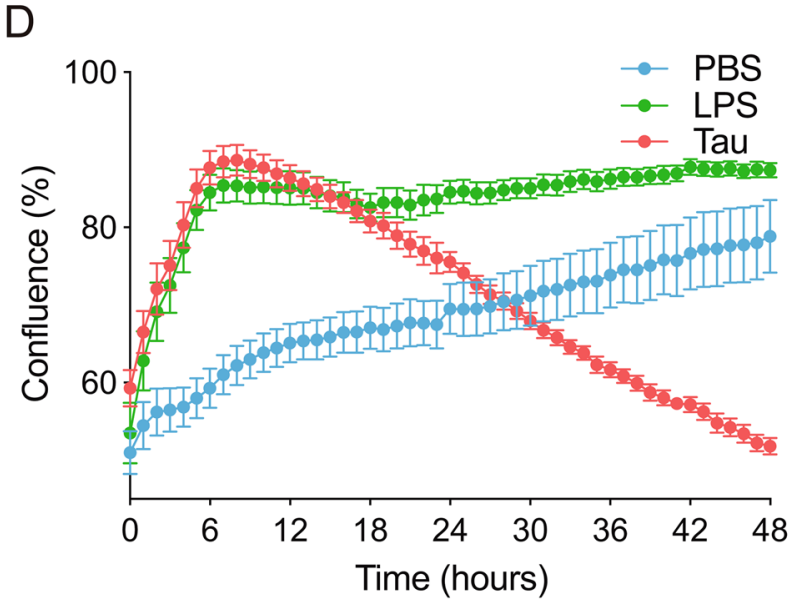

F

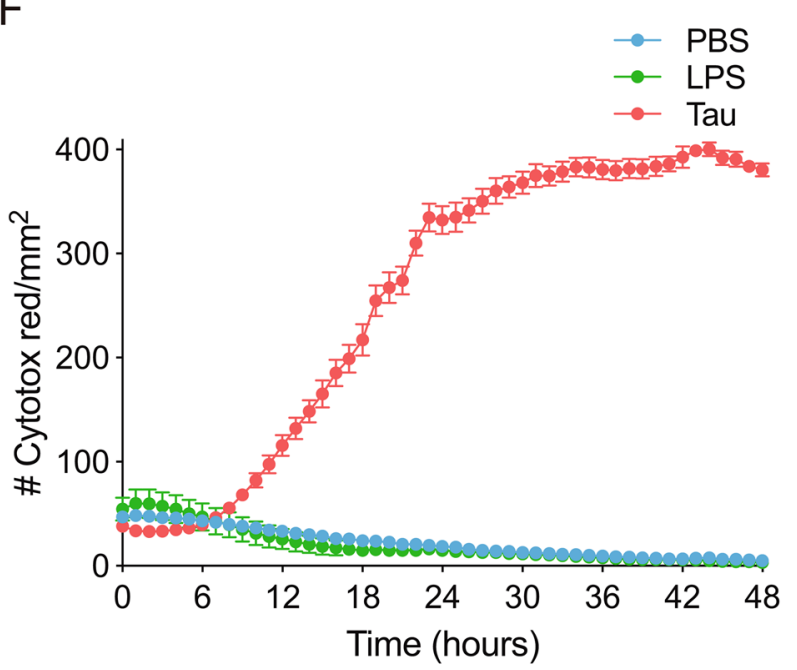

$24 \mathrm{~h}$
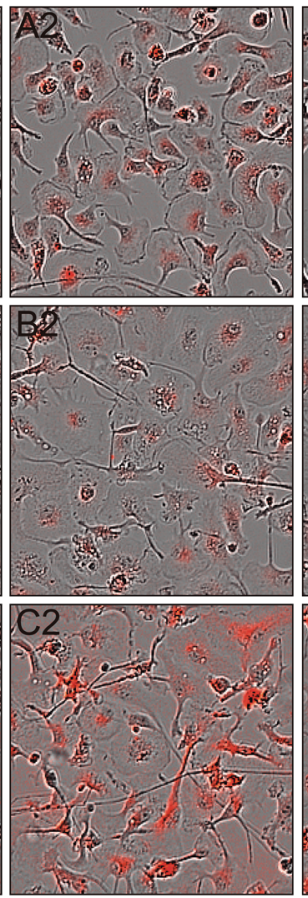

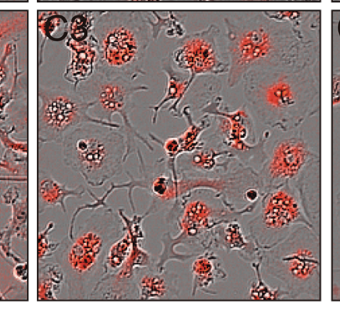

$\mathrm{E}$

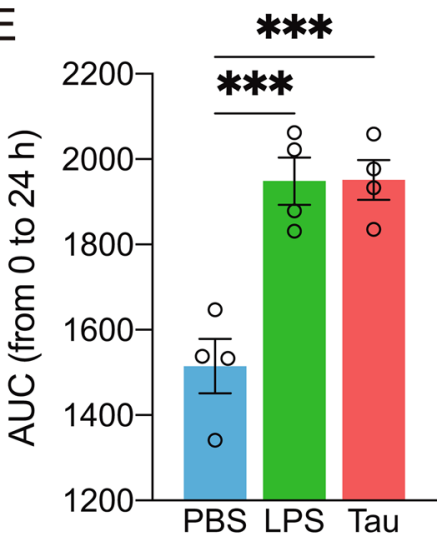

G

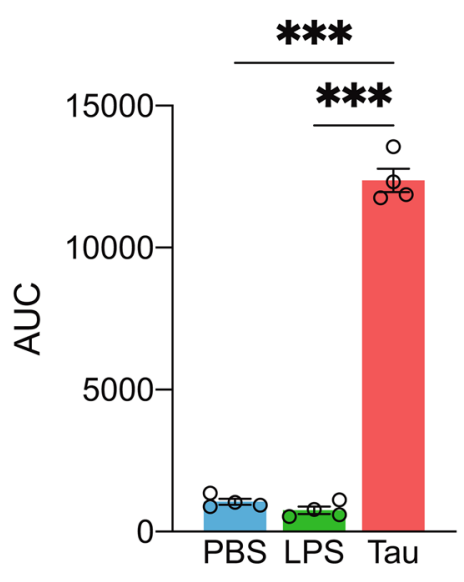



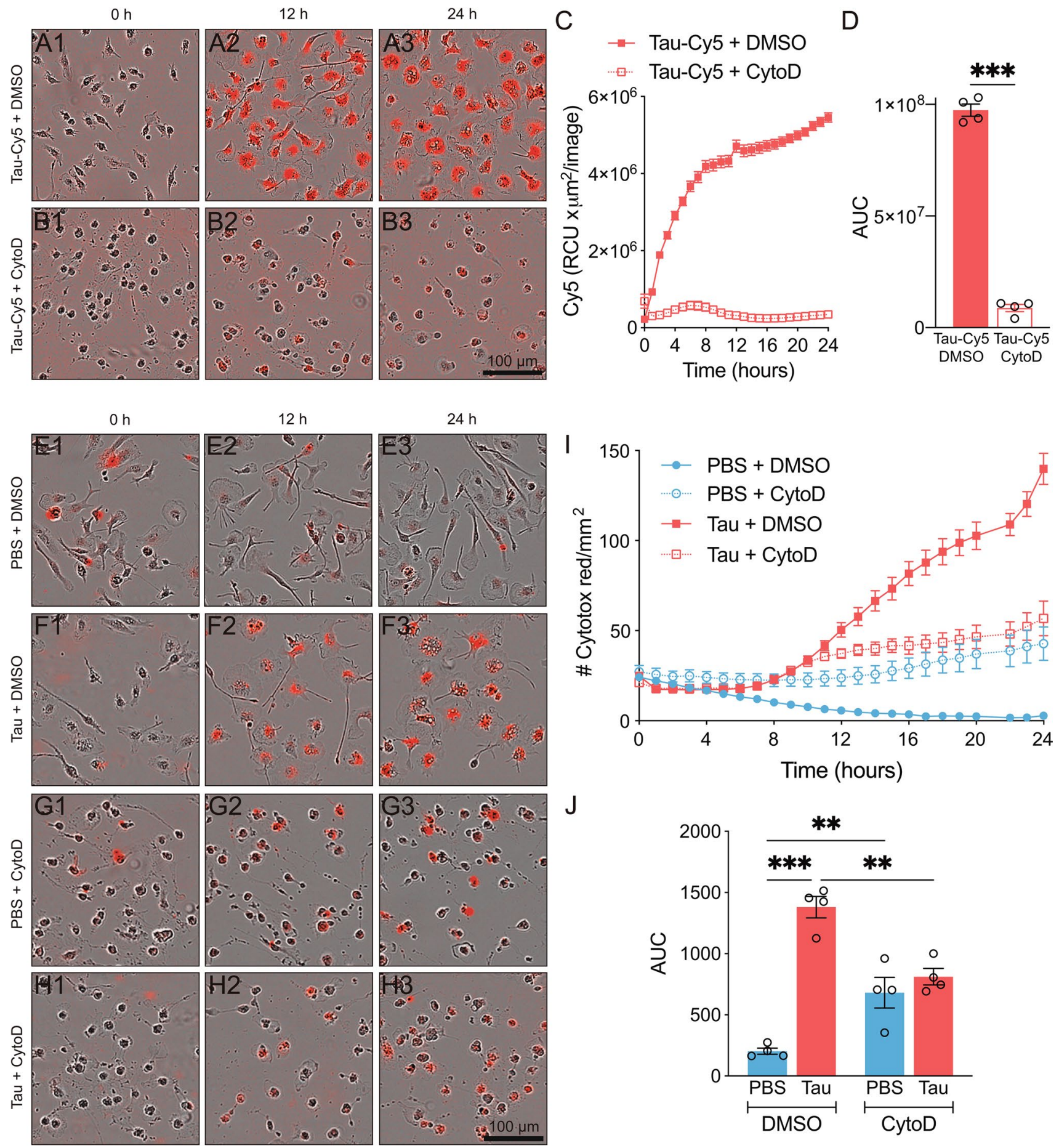

\section{$J$}

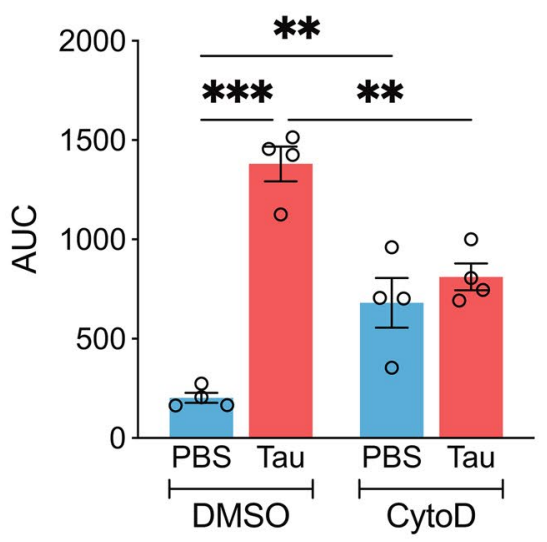

Fig. 2 Phagocytosis inhibition decreases tau-mediated cytotoxicity in microglia. Representative images of microglia treated with tau-Cy5 (red) in the absence (A) or presence of cytochalasin D (CytoD) (B) for $24 \mathrm{~h}$. (C-D) CytoD-mediated inhibition of phagocytosis prevents tau internalization. $* * * p<0.001$ from Student's $t$ test (two-tailed). Representative images of microglia treated for $24 \mathrm{~h}$ with PBS (control) (E and $\mathbf{G})$ and tau protein $(\mathbf{F}$ and $\mathbf{H})$ in the absence $(\mathbf{E}-\mathbf{F})$ or

presence of CytoD (G-H). Cytotox Red labeling indicates cytotoxicity. (I-J) Cytotoxicity analysis shows that phagocytosis inhibition decreases tau-mediated cytotoxicity. ${ }^{* *} p<0.01 ; * * * p<0.001$ from one-way ANOVA. $n=4$. Graphs show mean \pm SEM. Scale bars, $100 \mu \mathrm{m}$. AUC, area under the curve; DMSO, dimethyl sulfoxide; PBS, phosphate-buffered saline; RCU, total red object integrated density 
57]) activates $\mathrm{p} 38$ in these cells. For this purpose, we made use of a lentiviral vector (pWPI-Tau) (Fig. 4A) that allows the efficient expression of tau in $\mathrm{Bv}-2$ mouse microglia, as reported by the GFP reporter gene by flow cytometry (Fig. 4B) and western blot (Fig. 4C). Infected cells and their corresponding controls were treated with tau for $30 \mathrm{~min}$, and p38 activity was quantified by western blot (Fig. 4C), showing that this kinase was activated exclusively in the presence of exogenous tau (Fig. 4D).

\section{p38 Inhibition Decreases Tau-Mediated Cytotoxicity in Microglia}

Thus far, we have reported that the inhibition of tau phagocytosis decreased cytotoxicity in microglia (Fig. 2). However, this approach did not prevent $\mathrm{p} 38$ activation in these cells (Fig. 3). At this point, we sought to explore the possible beneficial effect of $\mathrm{p} 38$ inhibition on tau-mediated cytotoxicity. To this end, microglia were treated with SB for $30 \mathrm{~min}$ and tau was subsequently added for $24 \mathrm{~h}$. Cytotox Red analysis revealed that SB per se had no toxic effect on these cells (Fig. 5A, C, E-F). Moreover, we confirmed that tau promoted an increase in cell death (Figs. 5A-B, E-F), as we had previously observed (Fig. 1 and 2). However, tau-mediated cytotoxicity was considerably reduced when SB was present (Fig. 5B, D-F and Supplementary video S4). The analysis of cell death by flow cytometry confirmed these results (Supplementary Fig. S3), thereby indicating that p38 inhibition alleviates cytotoxicity in microglia treated with tau.

\section{p38 Inhibition Enhances Tau Phagocytosis by Microglia}

Given that tau accumulates in the extracellular space in certain neurodegenerative diseases [58] and that the phagocytic capacity of microglia decreases with age [59], the discovery of potential targets that enhance phagocytosis is crucial to ensure the maintenance of CNS homeostasis. In this context, we analyzed the effect of $\mathrm{p} 38$ inhibition on tau phagocytosis by microglia. Cells were subjected to a $30 \mathrm{~min}$ pre-treatment with $\mathrm{SB}$, and tau-Cy5 was subsequently added at different time points. A period between 1 and $6 \mathrm{~h}$ was chosen since there was not a drastic increase in cell death during this time interval (Fig. 1F). We observed that p38 inhibition increased tau phagocytosis in microglia (Fig. 6A-B). These data were further confirmed by flow cytometry (Supplementary Fig. S4).

In view of these results, we next sought to identify the mechanism responsible for this increase in tau internalization. Stancu et al. reported that tau is taken up by microglia and sorted to lysosomes [60]. Keeping this in mind, we studied whether there was an increase in the number of lysosomes. Using the Lysotracker Red probe, we detected an increase in lysosomal mass when cells were treated with SB (Fig. 6C-D). This observation thus suggests that p38 inhibition enhances tau phagocytosis through an increase in lysosome number.

\section{p38 Inhibition Partially Diminishes Tau-Mediated Microglial Migration}

Microglia constantly survey their environment thanks to their high motility, thus allowing them to rapidly detect changes in the brain parenchyma [61, 62]. During AD, NFTs (formed by the aggregation of hyperphosphorylated tau) act as an inflammatory focus, causing the surrounding microglia to approach the damaged area and exert a protective function [38]. However, studies analyzing the migration of microglia in the presence of tau are lacking. To address this gap, we performed an in vitro cell
A

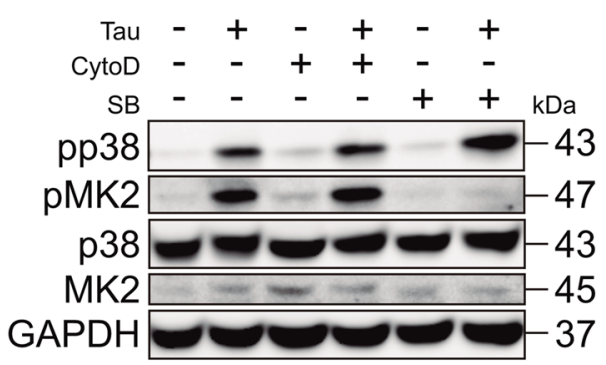

B

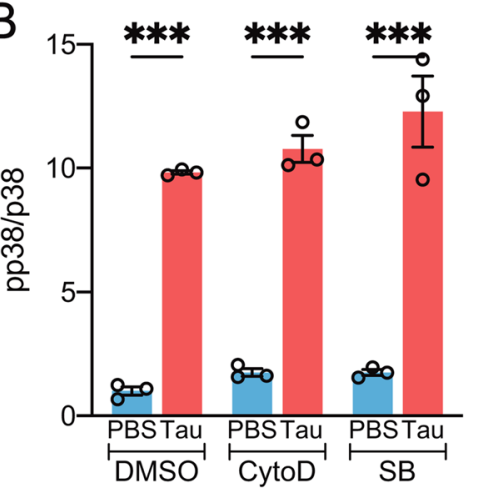

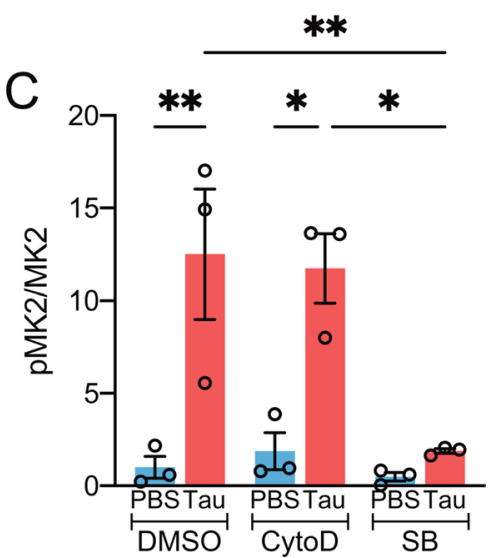

Fig. 3 Tau activates p38 independently of its internalization by microglia. Western blot (A) and quantification of p38 (B) and MK2 (C) activity in microglia treated for $30 \mathrm{~min}$ with PBS (control) and tau in the absence or presence of cytochalasin D (CytoD) or SB203580 (SB). Note that only in the presence of SB is tau-mediated p38 activation suppressed, as shown by the measurement of MK2 activity. $n=4$. Graphs show mean \pm SEM. ${ }^{*} p<0.05 ; * * p<0.01$; $* * * p<0.001$ from two-way ANOVA. DMSO, dimethyl sulfoxide; GAPDH, glyceraldehyde-3-phosphate dehydrogenase; MK2, MAPKactivated protein kinase 2; PBS, phosphate-buffered saline 
A

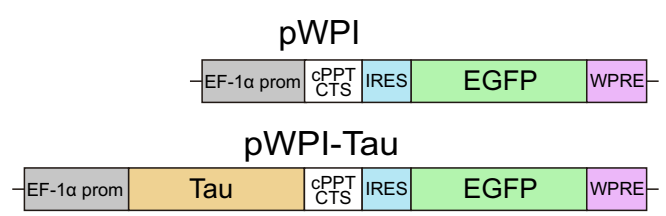

C

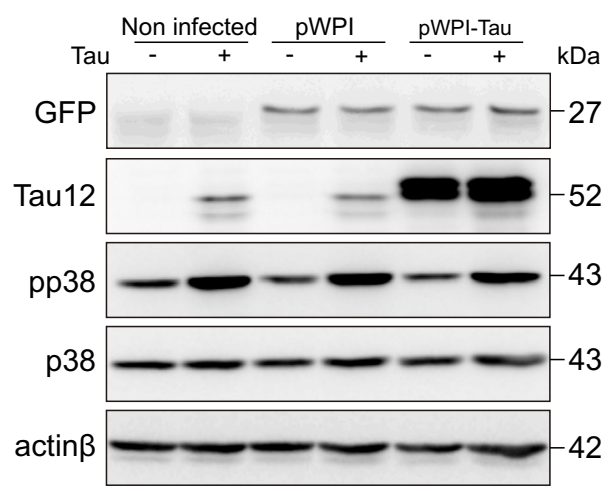

B
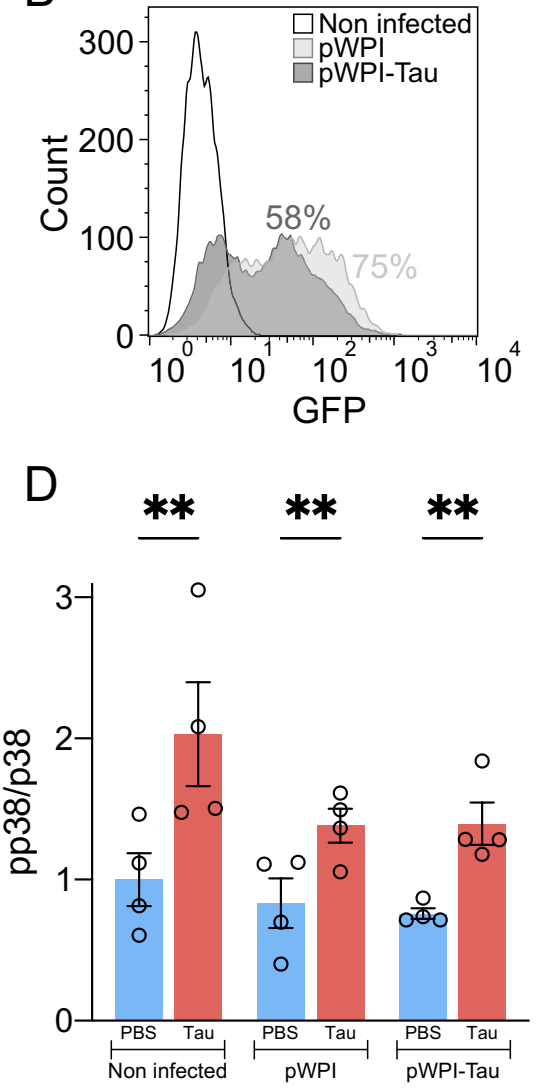

Fig. 4 p38 is specifically activated in the presence of extracellular tau. (A) pWPI (control) and pWPI-Tau lentiviral constructs used to induce tau protein expression in Bv-2 microglial cells. (B) GFP reporter was used to quantify the percentage of infection by flow cytometry. Western blot $(\mathbf{C})$ and quantification of p38 activity (D) in non-infected, pWPI-infected (control) and pWPI-Tau-infected Bv-2 cells treated for 30 min with PBS (control) and tau protein. Note that lentiviral infection and endogenous tau expression do not trigger p38

migration assay, which consisted of seeding the cells on an insert placed in a well with that its corresponding treatment (Fig. 7A). After $3 \mathrm{~h}$ of incubation under different experimental conditions, a significant increase in microglial migration in the presence of tau was observed. Nonetheless, simultaneous addition of SB and tau reduced the migration of these cells (Fig. 7B). To provide a possible explanation for this phenomenon, we analyzed the activity of heat shock protein 27 (Hsp27), a downstream target of p38 that regulates actin dynamics and, therefore, cell motility [63]. In this regard, western blot analysis showed an increase in Hsp27 activity when microglia were subjected to tau treatment. However, the addition of SB slightly reduced this activation (Fig. 7C-D). Additionally, a phalloidin staining was performed in order to analyze the dynamics of the actin cytoskeleton (Fig. 7E). When microglia were subjected to tau treatment, an increase in the proportion of migrating cells was observed (Fig. 7F). These activation. However, the addition of tau to the extracellular medium does achieve this activation. $n=4$. Graph shows mean $\pm \mathrm{SEM}$. $* * p<0.01$ from two-way ANOVA. cPPT/CTS, central polypurine tract/central termination sequence; EF- $1 \alpha$, elongation factor- $1 \alpha$; EGFP, enhanced green fluorescent protein; IRES, internal ribosome entry site; PBS, phosphate-buffered saline; WPRE, woodchuck hepatitis virus posttranscriptional regulatory element

cells are characterized by the presence of a large filopodium (orange arrows in Fig. 7E2) and their cytoplasmatic protrusions called filopodia. Consequently, microglia also increased their occupied area (Fig. 7G). However, as it was observed with the in vitro assay, the inhibition of $\mathrm{p} 38$ considerably reduced tau-mediated microglial migration.

\section{Discussion}

Tau pathology is a hallmark of several neurodegenerative diseases whose incidence has grown rapidly in recent years due to the aging of the world population. Current research has focused on the role of tau in health and disease, as well as on strategies to mitigate tau accumulation, prevent its aggregation and promote its clearance [64]. However, there is a substantial knowledge gap concerning the molecular pathways involved in tau-mediated toxicity 

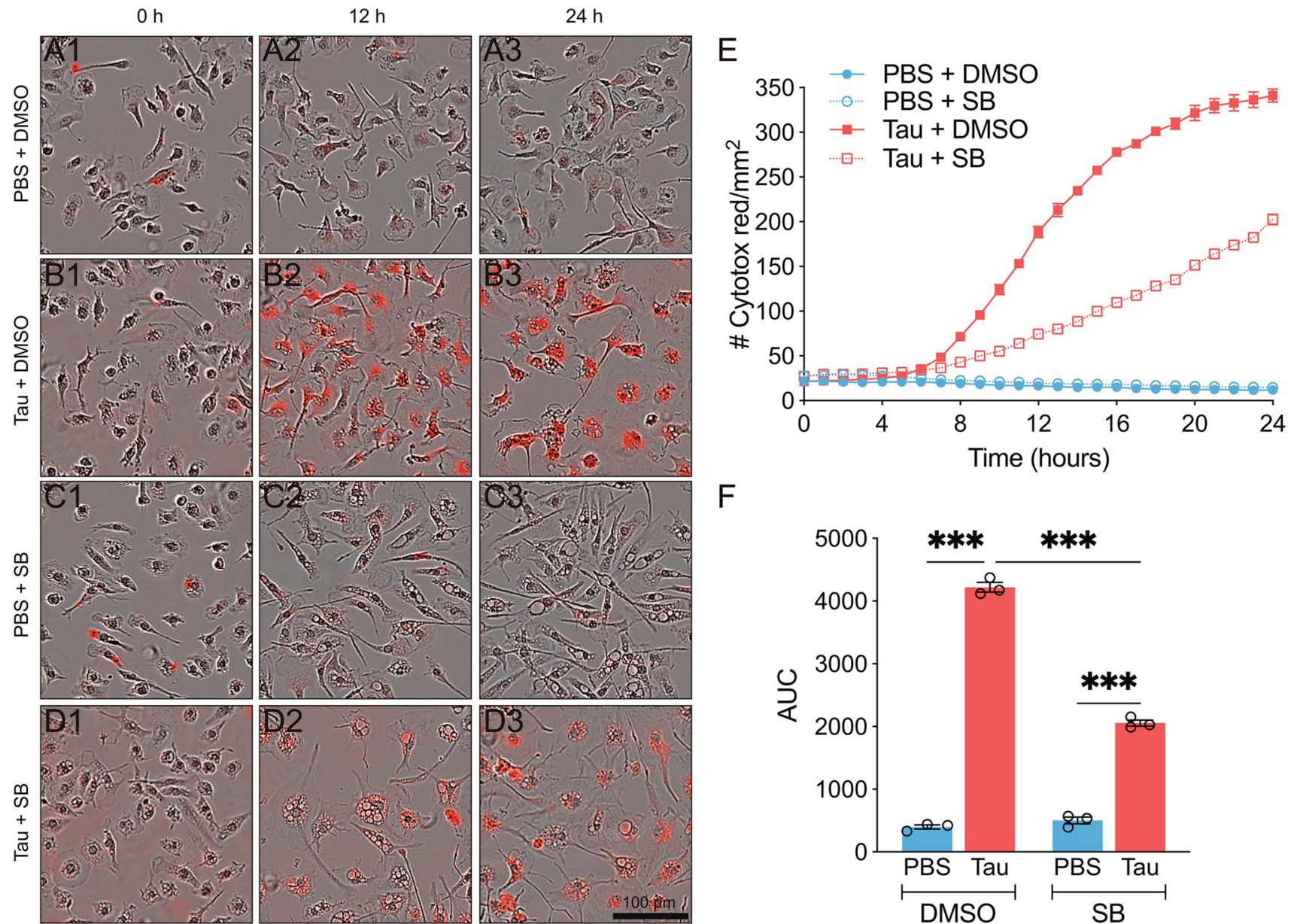

$\mathrm{F}$

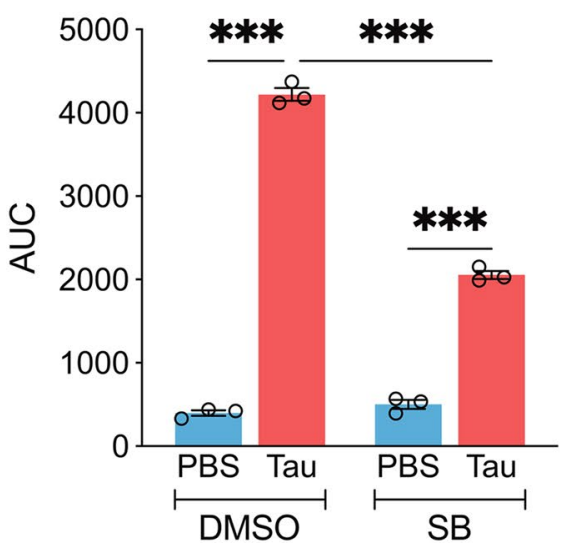

Fig. 5 p38 inhibition decreases tau-mediated cytotoxicity in microglia. Representative images of microglia treated for $24 \mathrm{~h}$ with PBS (control) (A and $\mathbf{C}$ ) or tau (B and D) in the absence (A-B) or presence of SB203580 (SB) (C-D). Cytotox Red labeling indicates cytotoxicity. (E-F) Cytotoxicity analysis shows that p38 inhi-

and neuroinflammation, thus hindering the identification of potential therapeutic targets for tauopathies such as AD. During the progression of this neurodegenerative disorder, neurons release various components into the extracellular space, including tau, usually as a result of neuronal death. However, these cells also present different mechanisms for the physiological release of tau, thus contributing to its propagation [54]. In this context, extracellular tau has a toxic effect on neuronal cells [52]. However, the repercussions on other cell types of the CNS, such as microglia, remain unexplored. To address this knowledge gap, we made use of primary microglia cultures in combination with live-cell imaging techniques and several in vitro assays to study tau toxicity in this cell population. While previous research shed light on the mechanism of tau internalization by microglia [32, 33, 51], this is the first study evidencing the toxic effect of extracellular tau on these cells. In this regard, inhibition of phagocytic bition decreases tau-mediated cytotoxicity. $n=3$. Graphs show mean \pm SEM. $* * * p<0.001$ from two-way ANOVA. Scale bar, $100 \mu \mathrm{m}$. AUC, area under the curve; DMSO, dimethyl sulfoxide; PBS, phosphate-buffered saline

function decreased tau-mediated cytotoxicity in microglia. However, the blockade of tau internalization did not prevent microglia from triggering an inflammatory response, as revealed by $\mathrm{p} 38$ activation.

The p38 MAPK signaling pathway is involved in a plethora of functions [43]. Although this kinase is expressed mainly in glia [56, 57], its role in the CNS has been associated with tau phosphorylation in neurons [65-67]. Nonetheless, recent research conducted by our group revealed that tau triggers an inflammatory response in microglia through p38 activation [41]. Also, that study showed that $\mathrm{p} 38$ inhibition reduces the levels of pro-inflammatory cytokines in microglia treated with tau. However, the effect of p38 blockade on tau-mediated cytotoxicity in these cells remained unknown. To address this question, here we demonstrate that $\mathrm{p} 38$ inhibition through SB203580 (SB) treatment decreases tau-mediated cytotoxicity in microglia. This finding is in agreement with 
Fig. 6 p38 inhibition enhances tau phagocytosis by microglia through an increase in lysosomal mass. (A-B) Time course of tau internalization by microglial cells in the absence or presence of SB203580 (SB). (C-D) Lysotracker red quantification reveals an increase in lysosomal mass when p38 is inhibited in microglial cells. $n=3-4$. Graphs show mean \pm SEM. $* * p<0.01$; $* * * p<0.001$ from Student's $t$ test (two-tailed). AUC, area under the curve; DMSO, dimethyl sulfoxide; MFI, mean fluorescence intensity; OD, optic density
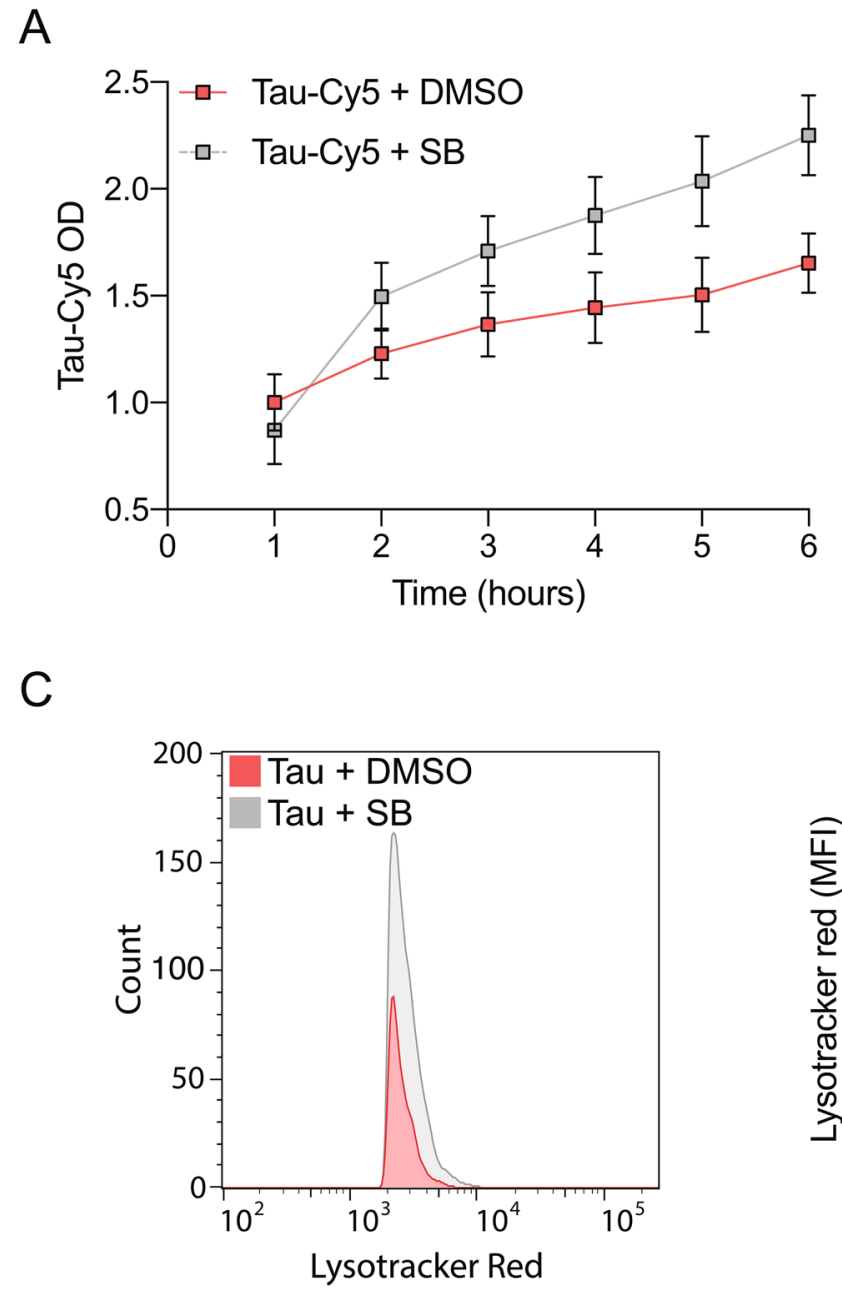

B
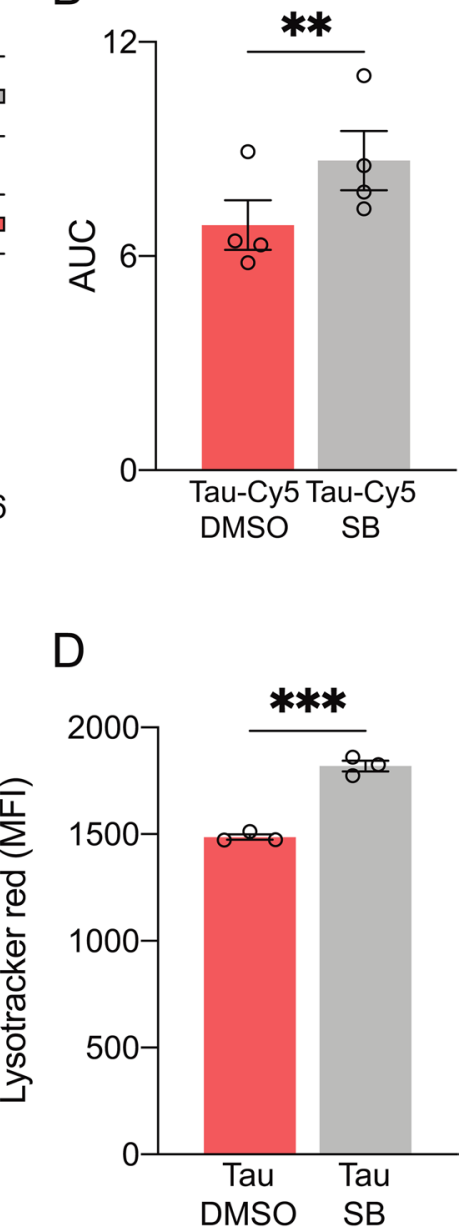

previous observations by Xia et al., who determined that p38 signaling is critical for the induction of cell death processes [68].

Since p38 inhibition markedly reduced the mortality of microglia, we next explored whether SB treatment had additional effects on certain functions of these cells, such as phagocytosis or migration. Regarding the former, the CNS requires an efficient system that eliminates potentially harmful components present in the extracellular space [53]. In this context, microglia can internalize tau in vitro and in vivo [33], and here we show that p38 inhibition increased tau phagocytosis by these cells. This finding is in line with those of other studies which indicate that enhanced microglial phagocytosis may offer an effective therapeutic strategy during aging and in several neurodegenerative diseases [32, 69, 70]. Conversely, Reed-Geaghan et al. reported that p38 inhibition reduces A $\beta$ phagocytosis [71]. This opposing effect could be attributed to distinct $A \beta$ - and tau-associated microglial profiles in $A D$ patients, which would support the notion that these cells have distinct phenotypes depending on the histopathological hallmark present [72].

In addition, this improvement in phagocytic function must be accompanied by effective molecular machinery capable of degrading toxic proteins. Consistent with this idea, recent studies reported that extracellular tau is internalized by microglia and sorted to lysosomes, which play an essential role in tau clearance $[60,73]$. Taking this into consideration, we observed that p38 inhibition promoted an increase in lysosomal mass, thereby indicating that SB treatment enhanced tau phagocytosis through an increment in the number of lysosomes. In line with these findings, several studies support the notion that p38 signaling plays a key function in the endocytic pathway [74-76]. However, little is known about the role of p38 and its specific inhibitors in lysosomal biogenesis [77]. In this sense, more research is needed to elucidate the precise molecular mechanisms that induce an increase in tau internalization. Such information would then help to identify potential therapeutic targets for tauopathies [78]. 
Fig. 7 p38 inhibition diminishes tau-mediated microglial migration. (A) Representative diagram of the device used for the migration assay. The cells are seeded on the insert through which they can gradually migrate towards the base of the well. (B) Migration analysis shows that tau promotes microglial migration. However, when tau and SB203580 (SB) are added simultaneously, migration is reduced. Western blot (C) and quantification of Hsp27 activity (D) in microglia treated for 30 min with PBS (control) and tau in the absence or presence of SB. (E) Representative images of microglia stained with phalloidin. Orange arrows indicate migrating cells, which are characterized by the presence of a large filopodium. Quantification of the proportion of migrating vs. non-migrating cells $(\mathbf{F})$ and the percentage of area occupied (G). $n=3-4$. Graphs show mean \pm SEM. ${ }^{*} p<0.05$; ** $p<0.01$ from twoway ANOVA. Scale bar, $50 \mu \mathrm{m}$. DMSO, dimethyl sulfoxide; GAPDH, glyceraldehyde3-phosphate dehydrogenase; Hsp27, heat shock protein 27; PBS, phosphate-buffered saline
A

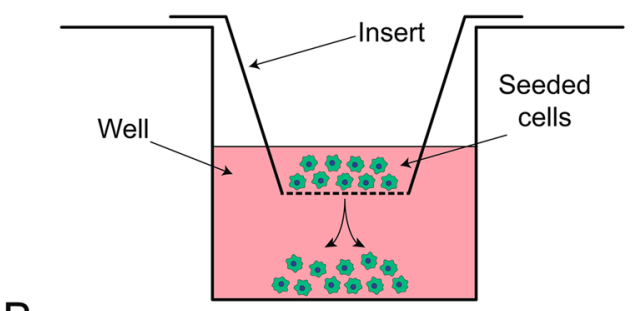

B

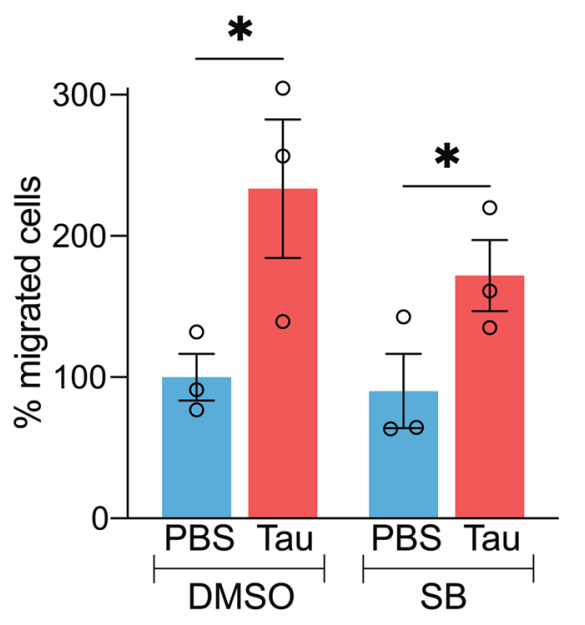

DMSO

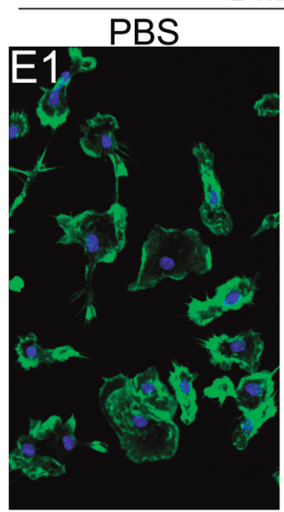

F
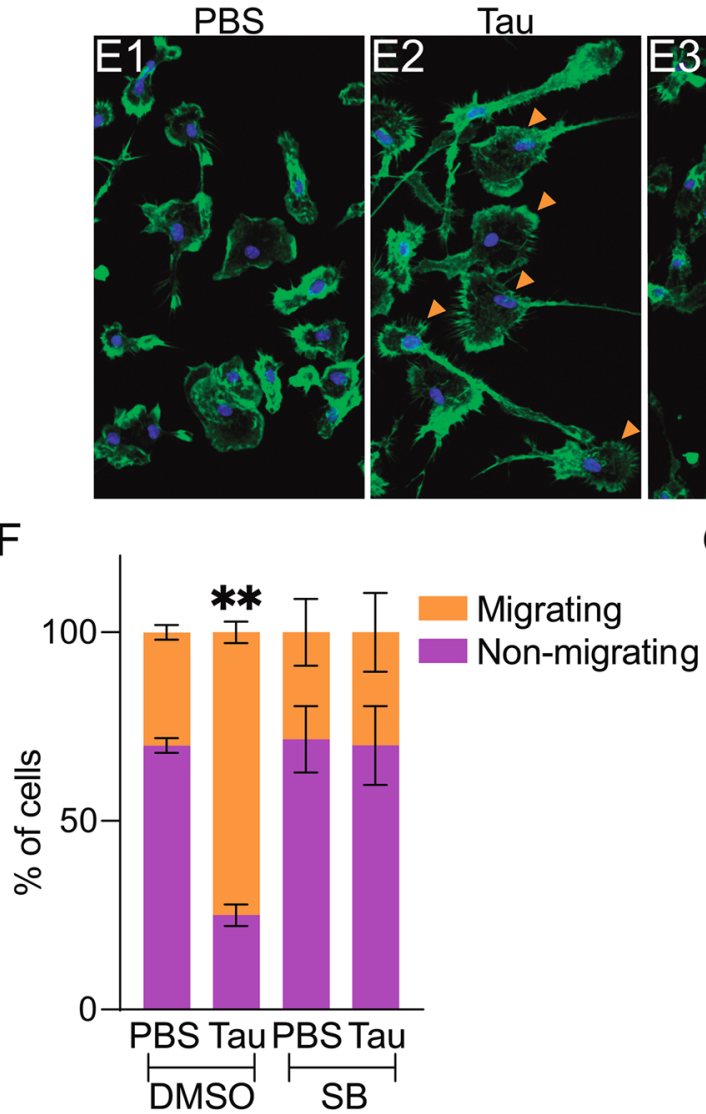

C
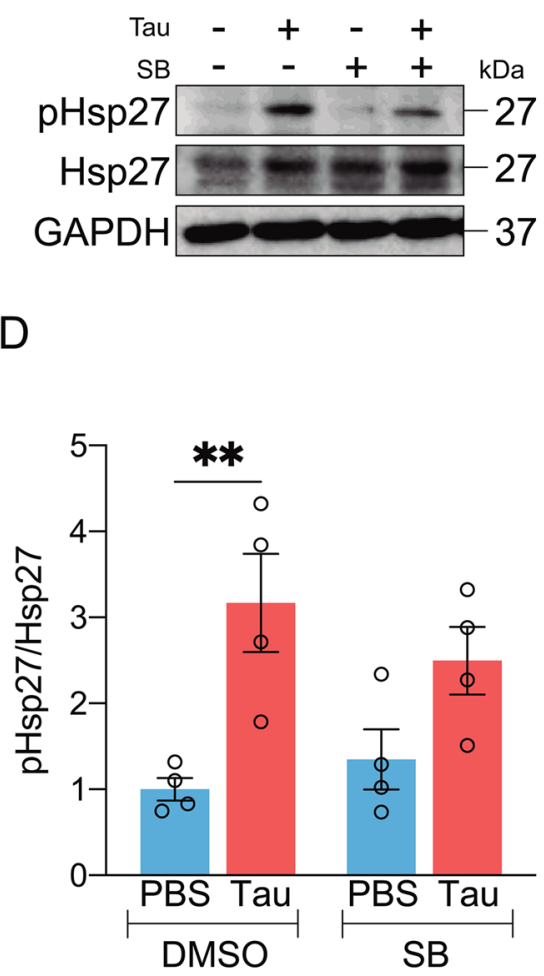

SB
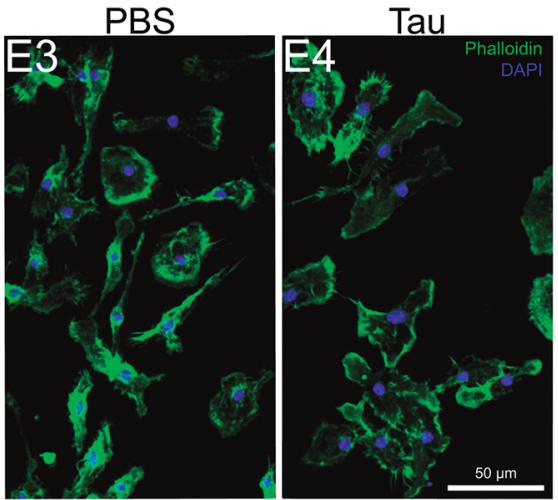

G

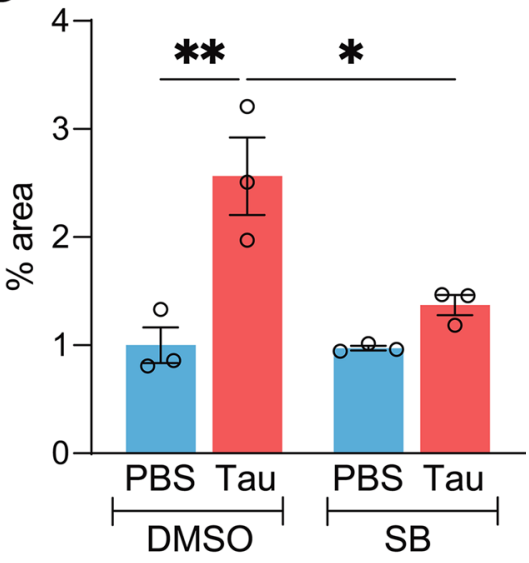


Regarding microglial migration, both senile plaques and NFTs act as inflammatory foci, thus causing surrounding microglia to approach them and exert their protective function $[38,79]$. While several authors have analyzed microglial migration in the context of $A \beta$ [80-82], studies that describe this phenomenon in the presence of tau are lacking. In this regard, we report that tau induced microglia migration in vitro. This observation, together with the ability of these cells to degrade tau [83], supports the neuroprotective role of microglia in tauopathies. However, the migratory capacity of microglia decreases with age [84, 85], and it is crucial to find strategies to strengthen this feature. Accordingly, we examined whether $\mathrm{p} 38$ inhibition could fulfill this function. Contrary to what was expected, we found that SB treatment decreased microglial migration. This observation could be explained by the fact that p38 activation promotes actin polymerization and, consequently, cell motility [63]. Based on this evidence, we analyzed the activity of Hsp27, an F-actin capping protein whose phosphorylation gives rise to actin polymerization [86]. We found that the enhanced microglial migration caused by the presence of extracellular tau was accompanied by an increase in the Hsp27 phosphorylation, while p38 inhibition had the opposite effect. These observations support the notion that $\mathrm{p} 38$ activation during inflammation serves as a homeostatic function to regulate actin dynamics, which would otherwise be destabilized during disease processes [63]. However, although p38 inhibition reduces microglial migration, this pharmacological treatment also has other beneficial effects capable of counteracting tau toxicity, namely, attenuation of inflammation, reduction in cell death and improvement of phagocytic function.

Another significant finding of this study is that endogenous tau expression did not lead to p38 activation, meaning that this signaling pathway is activated only when extracellular tau interacts with distinct membrane receptors. In this regard, there is previous evidence about the interaction of tau with the plasma membrane [87] and recent studies have characterized the binding of tau with several receptors in neurons (LRP1, M1 and M3) [27, 88 ] and astrocytes $(\alpha \mathrm{V} / \beta 1)$ [89]. Conversely, the interaction of tau with microglial receptors is poorly understood and it has only been described that tau binds to a specific microglia receptor named C-X3-C chemokine receptor 1 (CX3CR1) [51]. Zhuang et al. demonstrated that the natural ligand (C-X3-C chemokine ligand 1. CX3CL1) of this receptor triggers p38 activation in microglia [90]. Surprisingly, we found that extracellular tau also activated this kinase in $\mathrm{C}_{3} 3 \mathrm{Crl}^{-/-}$microglia (Supplementary Fig. S5). Taken together, these results suggest that tau interacts with other receptors involved in the p38 signaling cascade. In this sense, it is plausible that tau could be interacting with receptors of the innate immune system such as Toll-like or complement receptors, whose association with $\mathrm{A} \beta$ has already been described [91, 92]. However, studies based on the analysis of tau interactome have not yet identified any potential candidates [93-95]. Therefore, more research is needed to provide additional clues to understand the molecular mechanism underlying tau toxicity in microglia.

Current research efforts are focused on defining the dynamics of $\mathrm{p} 38$ activation $[96,97]$ with the aim of developing more efficient compounds. Accordingly, several p38 inhibitors have been tested in animal models of $A \beta$ accumulation [98-100], while less attention has been paid to tau pathology [101], in which we have recently shown that p38 activation occurs predominantly in microglia (in preparation). Regarding human clinical trials, neflamapimod (formerly known as VX-745) is the only p38 inhibitor that has completed phase 2 studies in patients with mild AD. The results of those trials indicated that a 24-week treatment did not improve episodic memory, although it caused a modest decrease in cerebrospinal fluid biomarkers associated with synaptic dysfunction. These findings thus suggest that a longer treatment at a higher dose would be needed to assess the effects on AD progression [102]. On the basis of our findings, future studies in humans require a distinction between $A \beta$, tau pathology, or their combination, to provide a comprehensive view of the effects of $\mathrm{p} 38$ inhibition in these patients.

In conclusion, our results make a significant contribution to enhancing our understanding of the dysregulated molecular mechanisms underlying tau toxicity in microglia. Moreover, our data reveal that p38 inhibition reduces the levels of pro-inflammatory cytokines, decreases cell death, and stimulates the phagocytic function of microglia, thus having a great impact on the resolution of neuroinflammation and extracellular tau clearance during tau pathology. Given these effects, p38 inhibition emerges as a potential therapeutic strategy for tauopathies.

Supplementary Information The online version contains supplementary material available at https://doi.org/10.1007/s12035-021-02715-0.

Acknowledgements The authors would like to thank the confocal microscopy and flow cytometry facilities at CBMSO for the technical assistance and Prof. Kenneth S. Kosik for the donation of the pWPITau plasmid.

Author Contribution J. R. P., R. C. and E. G. performed the experiments. V. G.-E. designed and generated the lentiviral vectors. R. M. M. designed phagocytosis and migration assays. J. R. P. analyzed the data. J. R. P., M. B., F. H. and J. A. contributed to the conception and design of the study. R. M. M., M. T. H. and J. A. obtained funding. J. R. P. wrote the paper. All authors read and approved the final manuscript.

Funding Open Access funding provided thanks to the CRUE-CSIC agreement with Springer Nature. This research was funded by the Spanish Ministry of Science and Innovation (BES-2015-074405, 
PGC2018-096177-B-I00) and the Center for Networked Biomedical Research on Neurodegenerative Diseases. Institutional grants from the Fundación Ramón Areces and Banco de Santander are also acknowledged. R. M. M. and M. T. H. are supported by the Helmholtz Association, under the project title "Immunology\&Inflammation," project number ZT-0027.

Data Availability The data that support the findings of this study are available from the corresponding author upon reasonable request.

Code Availability Not applicable.

\section{Declarations}

Ethics Approval Animal housing and maintenance protocols followed the guidelines of the Council of Europe Convention ETS123, revised as indicated in Directive 86/609/EEC. Animal experiments were performed under protocols (P15/P16/P18/P22) approved by the Institutional Animal Care and Utilization Committee (PROEX 291/15) and following ARRIVE guidelines.

Consent to Participate Not applicable.

Consent for Publication Not applicable.

Conflict of Interest M. T. H. is a clinical advisory board member at IFM Therapeutics, scientific advisory board member at Alector, associate editor of Neurology and Neuroinflammation, and honoraria for oral presentations from Pfizer, Novartis, Roche, Abbvie, and Biogen.

Open Access This article is licensed under a Creative Commons Attribution 4.0 International License, which permits use, sharing, adaptation, distribution and reproduction in any medium or format, as long as you give appropriate credit to the original author(s) and the source, provide a link to the Creative Commons licence, and indicate if changes were made. The images or other third party material in this article are included in the article's Creative Commons licence, unless indicated otherwise in a credit line to the material. If material is not included in the article's Creative Commons licence and your intended use is not permitted by statutory regulation or exceeds the permitted use, you will need to obtain permission directly from the copyright holder. To view a copy of this licence, visit http://creativecommons.org/licenses/by/4.0/.

\section{References}

1. Wimo A, Guerchet M, Ali G-C et al (2017) The worldwide costs of dementia 2015 and comparisons with 2010. Alzheimers Dement 13:1-7. https://doi.org/10.1016/j.jalz.2016.07.150

2. GBD (2016) Dementia Collaborators (2019) Global, regional, and national burden of Alzheimer's disease and other dementias, 1990-2016: a systematic analysis for the Global Burden of Disease Study 2016. Lancet Neurol 18:88-106. https://doi.org/ 10.1016/S1474-4422(18)30403-4

3. Masters CL, Simms G, Weinman NA et al (1985) Amyloid plaque core protein in Alzheimer disease and Down syndrome. Proc Natl Acad Sci USA 82:4245-4249. https://doi.org/10.1073/ pnas.82.12.4245

4. Jarrett JT, Berger EP, Lansbury PT (1993) The C-terminus of the beta protein is critical in amyloidogenesis. Ann N Y Acad Sci 695:144-148. https://doi.org/10.1111/j.1749-6632.1993.tb230 43. $x$
5. Maggio JE, Stimson ER, Ghilardi JR et al (1992) Reversible in vitro growth of Alzheimer disease beta-amyloid plaques by deposition of labeled amyloid peptide. Proc Natl Acad Sci USA 89:5462-5466. https://doi.org/10.1073/pnas.89.12.5462

6. Kidd M (1963) Paired helical filaments in electron microscopy of Alzheimer's disease. Nature 197:192-193. https://doi.org/10. 1038/197192b0

7. Crowther RA, Wischik CM (1985) Image reconstruction of the Alzheimer paired helical filament. EMBO J 4:3661-3665. https:// doi.org/10.1002/j.1460-2075.1985.tb04132.x

8. von Bergen M, Friedhoff P, Biernat J et al (2000) Assembly of tau protein into Alzheimer paired helical filaments depends on a local sequence motif ((306)VQIVYK(311)) forming beta structure. Proc Natl Acad Sci USA 97:5129-5134. https://doi.org/10. 1073/pnas.97.10.5129

9. Serrano-Pozo A, Frosch MP, Masliah E, Hyman BT (2011) Neuropathological alterations in Alzheimer disease. Cold Spring Harb Perspect Med 1:a006189. https://doi.org/10.1101/cshpe rspect.a006189

10. Weingarten MD, Lockwood AH, Hwo SY, Kirschner MW (1975) A protein factor essential for microtubule assembly. Proc Natl Acad Sci USA 72:1858-1862. https://doi.org/10.1073/pnas.72.5. 1858

11. Dixit R, Ross JL, Goldman YE, Holzbaur ELF (2008) Differential regulation of dynein and kinesin motor proteins by tau. Science 319:1086-1089. https://doi.org/10.1126/science.11529 93

12. Perea JR, Bolós M, Avila J (2020) Microglia in Alzheimer's disease in the context of tau pathology. Biomolecules 10:1439. https://doi.org/10.3390/biom10101439

13. Tapia-Rojas C, Cabezas-Opazo F, Deaton CA et al (2019) It's all about tau. Prog Neurobiol 175:54-76. https://doi.org/10.1016/j. pneurobio.2018.12.005

14. Rösler TW, Tayaranian Marvian A, Brendel M et al (2019) Fourrepeat tauopathies. Prog Neurobiol 180:101644. https://doi.org/ 10.1016/j.pneurobio.2019.101644

15. Grundke-Iqbal I, Iqbal K, Tung YC et al (1986) Abnormal phosphorylation of the microtubule-associated protein tau (tau) in Alzheimer cytoskeletal pathology. Proc Natl Acad Sci U S A 83:4913-4917. https://doi.org/10.1073/pnas.83.13.4913

16. Biernat J, Gustke N, Drewes G et al (1993) Phosphorylation of Ser262 strongly reduces binding of tau to microtubules: distinction between PHF-like immunoreactivity and microtubule binding. Neuron 11:153-163. https://doi.org/10.1016/0896-6273(93) 90279-Z

17. Bondareff W, Mountjoy CQ, Roth M, Hauser DL (1989) Neurofibrillary degeneration and neuronal loss in Alzheimer's disease. Neurobiol Aging 10:709-715. https://doi.org/10.1016/01974580(89)90007-9

18. Morsch R, Simon W, Coleman PD (1999) Neurons may live for decades with neurofibrillary tangles. J Neuropathol Exp Neurol 58:188-197. https://doi.org/10.1097/00005072-19990 2000-00008

19. Kuchibhotla KV, Wegmann S, Kopeikina KJ et al (2014) Neurofibrillary tangle-bearing neurons are functionally integrated in cortical circuits in vivo. Proc Natl Acad Sci USA 111:510-514. https://doi.org/10.1073/pnas.1318807111

20. Andorfer C, Acker CM, Kress Y et al (2005) Cell-cycle reentry and cell death in transgenic mice expressing nonmutant human tau isoforms. J Neurosci 25:5446-5454. https://doi.org/10.1523/ JNEUROSCI.4637-04.2005

21. Santacruz K, Lewis J, Spires T et al (2005) Tau suppression in a neurodegenerative mouse model improves memory function. Science 309:476-481. https://doi.org/10.1126/science.1113694

22. Sydow A, Van der Jeugd A, Zheng F et al (2011) Tau-induced defects in synaptic plasticity, learning, and memory are reversible 
in transgenic mice after switching off the toxic Tau mutant. J Neurosci 31:2511-2525. https://doi.org/10.1523/JNEUROSCI. 5245-10.2011

23. Van der Jeugd A, Hochgräfe K, Ahmed T et al (2012) Cognitive defects are reversible in inducible mice expressing pro-aggregant full-length human Tau. Acta Neuropathol 123:787-805. https:// doi.org/10.1007/s00401-012-0987-3

24. Cowan CM, Mudher A (2013) Are tau aggregates toxic or protective in tauopathies? Front Neurol 4:114. https://doi.org/10.3389/ fneur.2013.00114

25. Bengoa-Vergniory N, Velentza-Almpani E, Silva AM et al (2021) Tau-proximity ligation assay reveals extensive previously undetected pathology prior to neurofibrillary tangles in preclinical Alzheimer's disease. Acta Neuropathol Commun 9:1-20. https:// doi.org/10.1186/s40478-020-01117-y

26. Wu JW, Herman M, Liu L et al (2013) Small misfolded tau species are internalized via bulk endocytosis and anterogradely and retrogradely transported in neurons. J Biol Chem 288:18561870. https://doi.org/10.1074/jbc.M112.394528

27. Gómez-Ramos A, Díaz-Hernández M, Rubio A et al (2008) Extracellular tau promotes intracellular calcium increase through M1 and M3 muscarinic receptors in neuronal cells. Mol Cell Neurosci 37:673-681. https://doi.org/10.1016/j.men.2007.12.010

28. Holmes BB, DeVos SL, Kfoury N et al (2013) Heparan sulfate proteoglycans mediate internalization and propagation of specific proteopathic seeds. Proc Natl Acad Sci USA 110:E3138-E3147. https://doi.org/10.1073/pnas.1301440110

29. Calafate S, Flavin W, Verstreken P, Moechars D (2016) Loss of Bin 1 promotes the propagation of tau pathology. Cell Rep 17:931-940. https://doi.org/10.1016/j.celrep.2016.09.063

30. Martini-Stoica H, Cole AL, Swartzlander DB et al (2018) TFEB enhances astroglial uptake of extracellular tau species and reduces tau spreading. J Exp Med 215:2355-2377. https://doi. org/10.1084/jem.20172158

31. Perea JR, López E, Díez-Ballesteros JC et al (2019) Extracellular monomeric tau is internalized by astrocytes. Front Neurosci 13:442. https://doi.org/10.3389/fnins.2019.00442

32. Luo W, Liu W, Hu X et al (2015) Microglial internalization and degradation of pathological tau is enhanced by an anti-tau monoclonal antibody. Sci Rep 5:11161. https://doi.org/10.1038/srep1 1161

33. Bolós M, Llorens-Martín M, Jurado-Arjona J et al (2015) Direct evidence of internalization of tau by microglia in vitro and in vivo. J Alzheimers Dis 50:77-87. https://doi.org/10.3233/ JAD-150704

34. Alliot F, Godin I, Pessac B (1999) Microglia derive from progenitors, originating from the yolk sac, and which proliferate in the brain. Brain Res Dev Brain Res 117:145-152. https://doi.org/ 10.1016/s0165-3806(99)00113-3

35. Ginhoux F, Greter M, Leboeuf M et al (2010) Fate mapping analysis reveals that adult microglia derive from primitive macrophages. Science 330:841-845. https://doi.org/10.1126/science. 1194637

36. Lawson LJ, Perry VH, Dri P, Gordon S (1990) Heterogeneity in the distribution and morphology of microglia in the normal adult mouse brain. Neuroscience 39:151-170. https://doi.org/10.1016/ 0306-4522(90)90229-w

37. Alzheimer A (1910) Beiträge zur Kenntnis der pathologischen Neuroglia und ihrer Beziehungen zu den Abbauvorgängen im Nervengewebe. In: Histologische und histopathologische Arbeiten über die Grosshirnrinde mit besonderer Berücksichtigung der pathologischen Anatomie der Geisteskrankheiten. Gustav Fischer, Jena, pp 401-562

38. Cras P, Kawai M, Siedlak S, Perry G (1991) Microglia are associated with the extracellular neurofibrillary tangles of Alzheimer disease. Brain Res 558:312-314. https://doi.org/10.1016/00068993(91)90783-r

39. El Khoury J, Hickman SE, Thomas CA et al (1996) Scavenger receptor-mediated adhesion of microglia to beta-amyloid fibrils. Nature 382:716-719. https://doi.org/10.1038/382716a0

40. Ising $\mathrm{C}$, Venegas $\mathrm{C}$, Zhang $\mathrm{S}$ et al (2019) NLRP3 inflammasome activation drives tau pathology. Nature 575:669-673. https://doi. org/10.1038/s41586-019-1769-z

41. Perea JR, Ávila J, Bolós M (2018) Dephosphorylated rather than hyperphosphorylated tau triggers a pro-inflammatory profile in microglia through the p38 MAPK pathway. Exp Neurol 310:1421. https://doi.org/10.1016/j.expneurol.2018.08.007

42. Kyriakis JM, Avruch J (2012) Mammalian MAPK signal transduction pathways activated by stress and inflammation: a 10-year update. Physiol Rev 92:689-737. https://doi.org/10.1152/physr ev.00028.2011

43. Canovas B, Nebreda AR (2021) Diversity and versatility of p38 kinase signalling in health and disease. Nat Rev Mol Cell Biol 22:346-366. https://doi.org/10.1038/s41580-020-00322-w

44. Bachstetter AD, Van Eldik LJ (2010) The p38 MAP kinase family as regulators of proinflammatory cytokine production in degenerative diseases of the CNS. Aging Dis 1:199-211

45. Hensley K, Floyd RA, Zheng NY et al (1999) p38 kinase is activated in the Alzheimer's disease brain. J Neurochem 72:20532058. https://doi.org/10.1046/j.1471-4159.1999.0722053.x

46. Goedert M, Hasegawa M, Jakes R et al (1997) Phosphorylation of microtubule-associated protein tau by stress-activated protein kinases. FEBS Lett 409:57-62. https://doi.org/10.1016/s00145793(97)00483-3

47. Reynolds CH, Nebreda AR, Gibb GM et al (1997) Reactivating kinase/p38 phosphorylates tau protein in vitro. J Neurochem 69:191-198. https://doi.org/10.1046/j.1471-4159.1997.69010 191.x

48. Reynolds CH, Betts JC, Blackstock WP et al (2000) Phosphorylation sites on tau identified by nanoelectrospray mass spectrometry: differences in vitro between the mitogen-activated protein kinases ERK2, c-Jun N-terminal kinase and P38, and glycogen synthase kinase-3beta. J Neurochem 74:1587-1595. https://doi. org/10.1046/j.1471-4159.2000.0741587.x

49. Feijoo C, Campbell DG, Jakes R et al (2005) Evidence that phosphorylation of the microtubule-associated protein Tau by SAPK4/p38delta at Thr50 promotes microtubule assembly. J Cell Sci 118:397-408. https://doi.org/10.1242/jcs.01655

50. Bolós M, Pallas-Bazarra N, Terreros-Roncal J et al (2017) Soluble tau has devastating effects on the structural plasticity of hippocampal granule neurons. Transl Psychiatry 7:1267. https://doi. org/10.1038/s41398-017-0013-6

51. Bolós M, Llorens-Martín M, Perea J et al (2017) Absence of CX3CR1 impairs the internalization of tau by microglia. Mol Neurodegener 12:59. https://doi.org/10.1186/s13024-017-0200-1

52. Gómez-Ramos A, Díaz-Hernández M, Cuadros R et al (2006) Extracellular tau is toxic to neuronal cells. FEBS Lett 580:48424850. https://doi.org/10.1016/j.febslet.2006.07.078

53. Gabandé-Rodríguez E, Keane L, Capasso M (2020) Microglial phagocytosis in aging and Alzheimer's disease. J Neurosci Res 98:284-298. https://doi.org/10.1002/jnr.24419

54. Brunello CA, Merezhko M, Uronen R-L, Huttunen HJ (2019) Mechanisms of secretion and spreading of pathological tau protein. Cell Mol Life Sci. https://doi.org/10.1007/ s00018-019-03349-1

55. Elliott JA, Winn WC (1986) Treatment of alveolar macrophages with cytochalasin D inhibits uptake and subsequent growth of Legionella pneumophila. Infect Immun 51:31-36

56. Zhang Y, Chen K, Sloan SA et al (2014) An RNA-sequencing transcriptome and splicing database of glia, neurons, and 
vascular cells of the cerebral cortex. J Neurosci 34:11929-11947. https://doi.org/10.1523/JNEUROSCI.1860-14.2014

57. Zhang Y, Sloan SA, Clarke LE et al (2016) Purification and characterization of progenitor and mature human astrocytes reveals transcriptional and functional differences with mouse. Neuron 89:37-53. https://doi.org/10.1016/j.neuron.2015.11.013

58. Yamada K, Cirrito JR, Stewart FR et al (2011) In vivo microdialysis reveals age-dependent decrease of brain interstitial fluid tau levels in P301S human tau transgenic mice. J Neurosci 31:13110-13117. https://doi.org/10.1523/JNEUROSCI.2569-11. 2011

59. Vaughan DW, Peters A (1974) Neuroglial cells in the cerebral cortex of rats from young adulthood to old age: an electron microscope study. J Neurocytol 3:405-429. https://doi.org/10. 1007/bf01098730

60. Stancu I-C, Cremers N, Vanrusselt H et al (2019) Aggregated tau activates NLRP3-ASC inflammasome exacerbating exogenously seeded and non-exogenously seeded tau pathology in vivo. Acta Neuropathol 137:599-617. https://doi.org/10.1007/ s00401-018-01957-y

61. Davalos D, Grutzendler J, Yang G et al (2005) ATP mediates rapid microglial response to local brain injury in vivo. Nat Neurosci 8:752-758. https://doi.org/10.1038/nn1472

62. Nimmerjahn A, Kirchhoff F, Helmchen F (2005) Resting microglial cells are highly dynamic surveillants of brain parenchyma in vivo. Science 308:1314-1318. https://doi.org/10.1126/scien ce. 1110647

63. Guay J, Lambert H, Gingras-Breton G et al (1997) Regulation of actin filament dynamics by p38 map kinase-mediated phosphorylation of heat shock protein 27. J Cell Sci 110:357-368

64. Jadhav S, Avila J, Schöll M et al (2019) A walk through tau therapeutic strategies. Acta Neuropathol Commun 7:22. https:// doi.org/10.1186/s40478-019-0664-z

65. Kelleher I, Garwood C, Hanger DP et al (2007) Kinase activities increase during the development of tauopathy in htau mice. J Neurochem 103:2256-2267. https://doi.org/10.1111/j.14714159.2007.04930.x

66. Bhaskar K, Konerth M, Kokiko-Cochran ON et al (2010) Regulation of tau pathology by the microglial fractalkine receptor. Neuron 68:19-31. https://doi.org/10.1016/j.neuron.2010.08.023

67. Lee S, Xu G, Jay TR et al (2014) Opposing effects of membraneanchored CX3CL1 on amyloid and tau pathologies via the p38 MAPK pathway. J Neurosci 34:12538-12546. https://doi.org/10. 1523/JNEUROSCI.0853-14.2014

68. Xia Z, Dickens M, Raingeaud J et al (1995) Opposing effects of ERK and JNK-p38 MAP kinases on apoptosis. Science 270:1326-1331. https://doi.org/10.1126/science.270.5240.1326

69. Mosher KI, Wyss-Coray T (2014) Microglial dysfunction in brain aging and Alzheimer's disease. Biochem Pharmacol 88:594-604. https://doi.org/10.1016/j.bcp.2014.01.008

70. Pluvinage JV, Haney MS, Smith BAH et al (2019) CD22 blockade restores homeostatic microglial phagocytosis in ageing brains. Nature 568:187-192. https://doi.org/10.1038/ s41586-019-1088-4

71. Reed-Geaghan EG, Savage JC, Hise AG, Landreth GE (2009) CD14 and Toll-like receptors 2 and 4 are required for fibrillar A-stimulated microglial activation. J Neurosci 29:11982-11992. https://doi.org/10.1523/JNEUROSCI.3158-09.2009

72. Gerrits E, Brouwer N, Kooistra SM et al (2021) Distinct amyloid- $\beta$ and tau-associated microglia profiles in Alzheimer's disease. Acta Neuropathol 141:681-696. https://doi.org/10.1007/ s00401-021-02263-w

73. Andersson CR, Falsig J, Stavenhagen JB et al (2019) Antibodymediated clearance of tau in primary mouse microglial cultures requires Fcy-receptor binding and functional lysosomes. Sci Rep 9:1-12. https://doi.org/10.1038/s41598-019-41105-4
74. Cavalli V, Vilbois F, Corti M et al (2001) The stress-induced MAP kinase p38 regulates endocytic trafficking via the GDI:Rab5 complex. Mol Cell 7:421-432. https://doi.org/10. 1016/S1097-2765(01)00189-7

75. Fratti RA, Chua J, Deretic V (2003) Induction of p38 mitogenactivated protein kinase reduces early endosome autoantigen 1 (EEA1) recruitment to phagosomal membranes. J Biol Chem 278:46961-46967. https://doi.org/10.1074/jbc.M305225200

76. Pelkmans L, Fava E, Grabner H et al (2005) Genome-wide analysis of human kinases in clathrin- and caveolae/raft-mediated endocytosis. Nature 436:78-86. https://doi.org/10.1038/natur e03571

77. Yang C, Zhu Z, Tong BCK et al (2020) A stress response p38 MAP kinase inhibitor SB202190 promoted TFEB/TFE3-dependent autophagy and lysosomal biogenesis independent of p38. Redox Biol 32:101445. https://doi.org/10.1016/j.redox.2020. 101445

78. Jiang S, Bhaskar K (2020) Degradation and transmission of tau by autophagic-endolysosomal networks and potential therapeutic targets for tauopathy. Front Mol Neurosci 13:1-19. https://doi. org/10.3389/fnmol.2020.586731

79. Perlmutter LS, Barron E, Chui HC (1990) Morphologic association between microglia and senile plaque amyloid in Alzheimer's disease. Neurosci Lett 119:32-36. https://doi.org/10.1016/03043940(90)90748-X

80. Du YS, Chen X, Fu J et al (1996) RAGE and amyloid-beta peptide neurotoxicity in Alzheimer's disease. Nature 382:685-691. https://doi.org/10.1038/382685a0

81. Bolmont T, Haiss F, Eicke D et al (2008) Dynamics of the microglial/amyloid interaction indicate a role in plaque maintenance. J Neurosci 28:4283-4292. https://doi.org/10.1523/JNEUROSCI. 4814-07.2008

82. Meyer-Luehmann M, Spires-Jones TL, Prada C et al (2008) Rapid appearance and local toxicity of amyloid-beta plaques in a mouse model of Alzheimer's disease. Nature 451:720-724. https://doi.org/10.1038/nature06616

83. Behrendt A, Bichmann M, Ercan-Herbst E et al (2019) Asparagine endopeptidase cleaves tau at N167 after uptake into microglia. Neurobiol Dis 130:104518. https://doi.org/10.1016/j.nbd. 2019.104518

84. Damani MR, Zhao L, Fontainhas AM et al (2011) Age-related alterations in the dynamic behavior of microglia. Aging Cell 10:263-276. https://doi.org/10.1111/j.1474-9726.2010.00660.x

85. Fang Y, Wang J, Yao L et al (2018) The adhesion and migration of microglia to $\beta$-amyloid $(A \beta)$ is decreased with aging and inhibited by Nogo/NgR pathway. J Neuroinflammation 15:210. https://doi.org/10.1186/s12974-018-1250-1

86. Benndorf R, Hayeß K, Ryazantsev S et al (1994) Phosphorylation and supramolecular organization of murine small heat shock protein HSP25 abolish its actin polymerization-inhibiting activity. J Biol Chem 269:20780-20784. https://doi.org/10.1016/s00219258(17)32060-4

87. Arrasate M, Pérez M, Avila J (2000) Tau dephosphorylation at tau-1 site correlates with its association to cell membrane. Neurochem Res 25:43-50. https://doi.org/10.1023/A:1007583214 722

88. Rauch JN, Luna G, Guzman E et al (2020) LRP1 is a master regulator of tau uptake and spread. Nature 580:381-385. https:// doi.org/10.1038/s41586-020-2156-5

89. Wang P, Ye Y (2021) Filamentous recombinant human tau activates primary astrocytes via an integrin receptor complex. Nat Commun 12:95. https://doi.org/10.1038/s41467-020-20322-w

90. Zhuang Z-Y, Kawasaki Y, Tan P-H et al (2007) Role of the CX3CR1/p38 MAPK pathway in spinal microglia for the development of neuropathic pain following nerve injury-induced 
cleavage of fractalkine. Brain Behav Immun 21:642-651. https:// doi.org/10.1016/j.bbi.2006.11.003

91. Doens D, Fernández PL (2014) Microglia receptors and their implications in the response to amyloid $\beta$ for Alzheimer's disease pathogenesis. J Neuroinflammation 11:48. https://doi.org/ 10.1186/1742-2094-11-48

92. Momtazmanesh S, Perry G, Rezaei N (2020) Toll-like receptors in Alzheimer's disease. J Neuroimmunol 348:577362. https://doi. org/10.1016/j.jneuroim.2020.577362

93. Gunawardana CG, Mehrabian M, Wang X et al (2015) The human tau interactome: binding to the ribonucleoproteome, and impaired binding of the proline-to-leucine mutant at position 301 (P301L) to chaperones and the proteasome. Mol Cell Proteomics 14:3000-3014. https://doi.org/10.1074/mcp.M115.050724

94. Stefanoska K, Volkerling A, Bertz J et al (2018) An N-terminal motif unique to primate tau enables differential protein-protein interactions. J Biol Chem 293:3710-3719. https://doi.org/10. 1074/jbc.RA118.001784

95. Luck K, Kim D-K, Lambourne L et al (2020) A reference map of the human binary protein interactome. Nature. https://doi.org/ 10.1038/s41586-020-2188-x

96. Tomida T, Takekawa M, Saito H (2015) Oscillation of p38 activity controls efficient pro-inflammatory gene expression. Nat Commun 6:4-6. https://doi.org/10.1038/ncomms9350

97. Kumar GS, Clarkson MW, Kunze MBA et al (2018) Dynamic activation and regulation of the mitogen-activated protein kinase p38. Proc Natl Acad Sci USA 115:4655-4660. https://doi.org/10. 1073/pnas.1721441115

98. Munoz L, Ralay Ranaivo H, Roy SM et al (2007) A novel p38 alpha MAPK inhibitor suppresses brain proinflammatory cytokine up-regulation and attenuates synaptic dysfunction and behavioral deficits in an Alzheimer's disease mouse model. J Neuroinflammation 4:21. https://doi.org/10.1186/ 1742-2094-4-21

99. Roy SM, Grum-Tokars VL, Schavocky JP et al (2015) Targeting human central nervous system protein kinases: An isoform selective p38 $\alpha$ MAPK inhibitor that attenuates disease progression in Alzheimer's disease mouse models. ACS Chem Neurosci 6:666-680. https://doi.org/10.1021/acschemneuro.5b00002

100. Gee MS, Son SH, Jeon SH et al (2020) A selective p38 $\alpha / \beta$ MAPK inhibitor alleviates neuropathology and cognitive impairment, and modulates microglia function in 5XFAD mouse. Alzheimers Res Ther 12:45. https://doi.org/10.1186/s13195-020-00617-2

101. Maphis N, Jiang S, Xu G et al (2016) Selective suppression of the $\alpha$ isoform of $\mathrm{p} 38$ MAPK rescues late-stage tau pathology. Alzheimers Res Ther 8:54. https://doi.org/10.1186/s13195-016-0221-y

102. Prins ND, Harrison JE, Chu H-M et al (2021) A phase 2 doubleblind placebo-controlled 24-week treatment clinical study of the p38 alpha kinase inhibitor neflamapimod in mild Alzheimer's disease. Alzheimers Res Ther 13:106. https://doi.org/10.1186/ s13195-021-00843-2

Publisher's Note Springer Nature remains neutral with regard to jurisdictional claims in published maps and institutional affiliations. 